\title{
Contrasting Impacts of Radiative Forcing in the Southern Ocean versus Southern Tropics on ITCZ Position and Energy Transport in One GFDL Climate Model
}

\author{
BAOQIANG XIANG \\ NOAA/Geophysical Fluid Dynamics Laboratory, Princeton, New Jersey, and University Corporation for \\ Atmospheric Research, Boulder, Colorado \\ MING ZHAO AND YI MING \\ NOAA/Geophysical Fluid Dynamics Laboratory, Princeton, New Jersey
}

WEIDONG YU

Center for Ocean and Climate Research, First Institute of Oceanography, State Oceanic Administration, and Laboratory for Regional Oceanography and Numerical Modeling, Qingdao National Laboratory for Marine Science and Technology, Qingdao, China

SARAH M. KANG

School of Urban and Environmental Engineering, Ulsan National Institute of Science and Technology, Ulsan, South Korea

(Manuscript received 22 August 2017, in final form 8 April 2018)

\begin{abstract}
Most current climate models suffer from pronounced cloud and radiation biases in the Southern Ocean (SO) and in the tropics. Using one GFDL climate model, this study investigates the migration of the intertropical convergence zone (ITCZ) with prescribed top-of-the-atmosphere (TOA) shortwave radiative heating in the SO $\left(50^{\circ}-80^{\circ} \mathrm{S}\right)$ versus the southern tropics $\left(\mathrm{ST} ; 0^{\circ}-20^{\circ} \mathrm{S}\right)$. Results demonstrate that the ITCZ position response to the ST forcing is twice as strong as the SO forcing, which is primarily driven by the contrasting sea surface temperature (SST) gradient over the tropics; however, the mechanism for the formation of the SST pattern remains elusive. Energy budget analysis reveals that the conventional energetic constraint framework is inadequate in explaining the ITCZ shift in these two perturbed experiments. For both cases, the anomalous Hadley circulation does not contribute to transport the imposed energy from the Southern Hemisphere to the Northern Hemisphere, given a positive mean gross moist stability in the equatorial region. Changes in the cross-equatorial atmospheric energy are primarily transported by atmospheric transient eddies when the anomalous ITCZ shift is most pronounced during December-May. The partitioning of energy transport between the atmosphere and ocean shows latitudinal dependence: the atmosphere and ocean play an overall equivalent role in transporting the imposed energy for the extratropical SO forcing, while for the ST forcing, the imposed energy is nearly completely transported by the atmosphere. This contrast originates from the different ocean heat uptake and also the different meridional scale of the anomalous ocean circulation.
\end{abstract}

\section{Introduction}

The spurious double ITCZ (DI) problem, characterized by excessive precipitation to the south of the equator, is a long-standing issue for current climate models (e.g., Lin 2007; Mechoso et al. 1995). Many

\footnotetext{
Corresponding author: Baoqiang Xiang, Baoqiang.xiang@noaa. gov
}

studies argued that the DI problem is tightly linked to the convection parameterization, such as the deep convection threshold (e.g., Bellucci et al. 2010), convection closure (Zhang and Wang 2006), and lateral entrainment (Hirota et al. 2011). The presence of relatively high sea surface temperature (SST) biases in the southeastern Pacific and Atlantic also contributes to the DI problem (e.g., Song and Zhang 2017; Richter 2015). 
In addition, previous studies underlined the importance of flux biases at the top of the atmosphere (TOA) and the surface in driving the spurious DI problem. For example, Xiang et al. (2017) argued that the intermodel spread of the DI problem in phase 5 of the Coupled Model Intercomparison Project (CMIP5) coupled models primarily originates from the tropics and from the TOA or surface fluxes in their atmospheric models. Meanwhile, current climate models suffer from a common bias with underestimated cloud amount and thus overestimated incoming shortwave radiation in the Southern Ocean (e.g., Trenberth and Fasullo 2010; Hwang and Frierson 2013). This is evident from the multimodel ensemble (MME) mean results of 19 CMIP5 models (Fig. 1a). Based on the energetic constraint framework, this Southern Ocean radiation bias was proposed to drive a northward cross-equatorial atmospheric energy transport (AET) that, in turn, forces an anomalous Hadley cell and the southward migration of ITCZ (Hwang and Frierson 2013).

The above hypothesis to link ITCZ migration to the AET is generally consistent with other studies with thermal perturbations at high latitudes using atmospheric models coupled to slab-ocean models (e.g., Broccoli et al. 2006; Chiang and Bitz 2005; Kang et al. 2009; Kang et al. 2008; Seo et al. 2014). Furthermore, Seo et al. (2014) found that the extratropical surface forcing is even more effective in shifting ITCZ position than the tropical surface forcing using one atmospheric model coupled to a slab-ocean model in an aquaplanet configuration. However, the above hypothesis was challenged by several recent studies using a complex coupled general circulation model (CGCM) with realistic geography: the ITCZ location is fairly insensitive to extratropical perturbations in fully coupled models (Deser et al. 2015; Hawcroft et al. 2016; Kay et al. 2016; Tomas et al. 2016). The reason behind this was attributed to the fact that the associated energy transport primarily occurs in the ocean rather than in the atmosphere.

A fundamental question then arises: What factors are responsible for the partitioning of energy transport between the atmosphere and ocean? In the tropics, the ocean usually plays a more important role in transporting energy. Given a similar magnitude of mass flux transport between the atmosphere and ocean associated with the Hadley circulation, the ocean is more effective in transporting energy. This was largely because the atmosphere has a positive but smaller mean gross moist stability (GMS) than that of the ocean (Held 2001; Czaja and Marshall 2006). The GMS was originally proposed in Neelin and Held (1987) as a measure of how efficiently divergent flow exports moist static energy (MSE). Some previous studies with perturbed forcing in the extratropics underlined the more important role of the ocean in transporting energy than the atmosphere (Deser et al. 2015; Hawcroft et al. 2016; Kay et al. 2016; Tomas et al. 2016) and are broadly consistent with these theoretical works. Meanwhile, some other factors, such as the highly model-dependent SST-stratocumulus feedback, may also be critical in determining the partitioning of energy transport as well as the tropical precipitation response to the extratropical forcing (Mechoso et al. 2016).

Given the pronounced extratropical and tropical radiation biases (Fig. 1a) and the diverse model sensitivity to the extratropical forcing, this study explores the ITCZ shift to prescribed idealized radiative forcing in the Southern Ocean and southern tropics using one climate model. The goal is to gain insight on 1) the formation of spurious DI problems in climate models, and 2) the physical processes determining the partitioning of energy transport between the atmosphere and ocean.

This paper is organized as follows. Section 2 introduces data, model, experiments, and analysis methodology. The mean state of the coupled control simulation is discussed in section 3. Section 4 investigates the imposed forcing and the associated model responses. The potential linkage among ITCZ shift, energy transport, and SST forcing is examined in section 5. Finally, in section 6 we summarize the major findings in this study together with some discussion.

\section{Data, model, experiments, and analysis methodology}

\section{a. Data}

Several observational datasets are used, consisting of precipitation from the Global Precipitation Climatology Project version 2.2 (GPCP; Adler et al. 2003), SST and sea ice concentration from the Met Office Hadley Centre Sea Ice and Sea Surface Temperature dataset (HadISST1; Rayner et al. 2003), and radiative fluxes from Clouds and the Earth's Radiant Energy System version 2.8 (CERES; Wielicki et al. 1996). The 19 CMIP5 historical simulations (Taylor et al. 2012) used here are the same as those used in Xiang et al. (2017). We use the time period of 1979-2005 for our analysis.

\section{b. Model}

We use a developmental version of the Geophysical Fluid Dynamics Laboratory (GFDL) next-generation Atmospheric Model, version 4 (AM4; Zhao et al. 2018), as well as a fully coupled model using AM4 coupled with the ocean model used in GFDL Forecast-Oriented Low Ocean Resolution (FLOR) model (Vecchi et al. 2014). 
CMIP5 model bias

a) TOA SW radiation

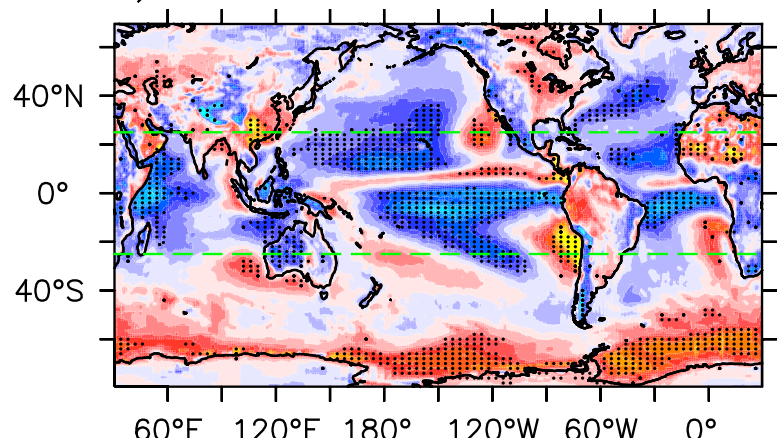

GFDL model bias

d) TOA SW radiation
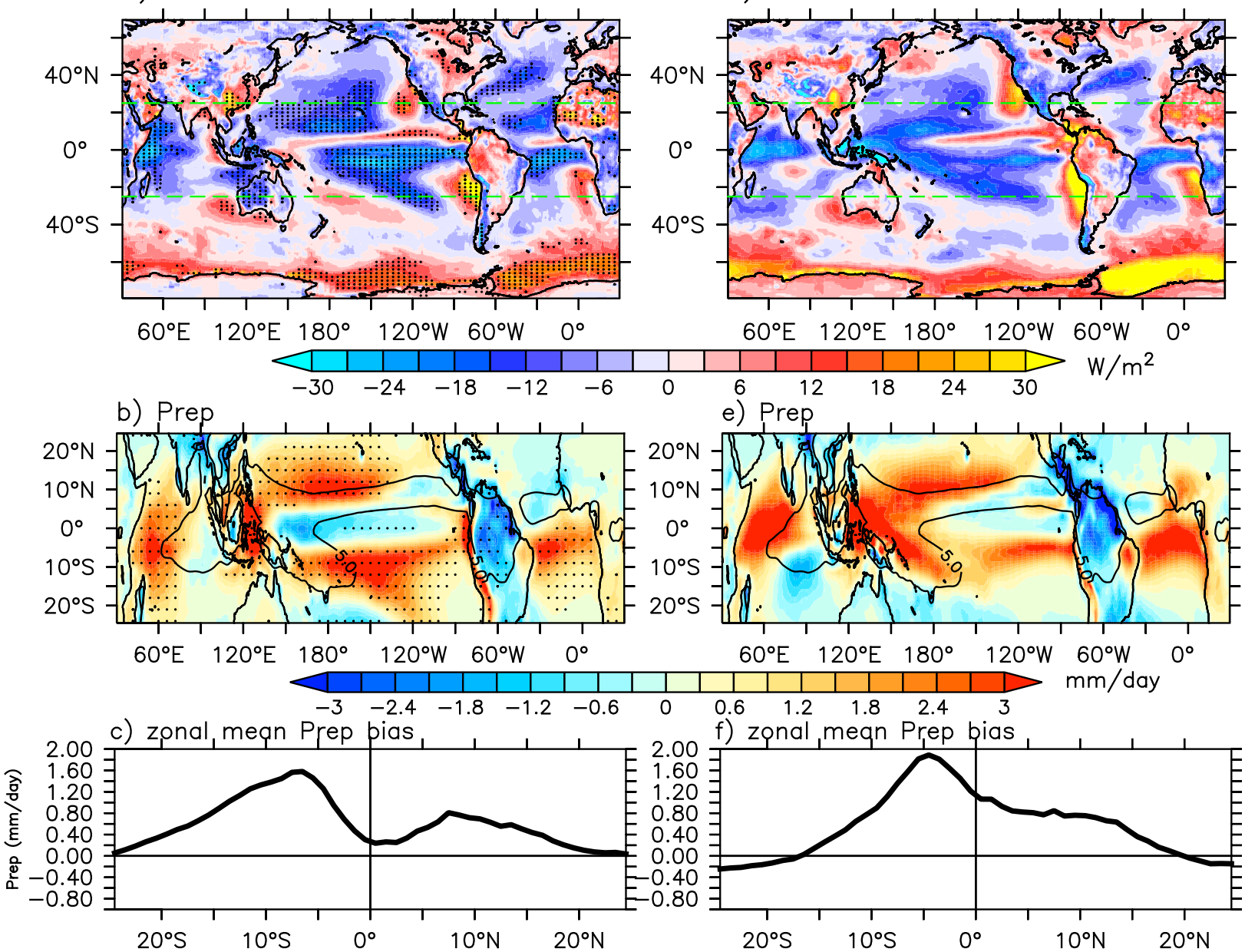

FIG. 1. Biases of annual mean (a) shortwave absorption and (b) precipitation from the MME mean of 19 CMIP5 coupled models. Stippling denotes regions where 16 (or more) out of 19 models have the same sign as the MME mean. The green dashed line in (a) shows the precipitation domain in (b). Observational climatological mean precipitation is shown as contours ( $\mathrm{mm} \mathrm{day}^{-1}$ ) in (b). (c) The zonal mean precipitation bias from the MME mean of CMIP5 coupled models. (d)-(f) As in (a)-(c), but for results from the one version of the GFDL model used in this study.

Both the atmospheric and oceanic models have an approximate $1^{\circ}$ horizontal resolution. The atmospheric model has 32 vertical levels and the oceanic model has 50 vertical levels.

\section{c. Experiments}

In this study, we performed 10 experiments: 4 fully coupled experiments, and 6 Atmospheric Model Intercomparison Project (AMIP) experiments with prescribed boundary forcing (Table 1 ).

\section{1) Fully COUPLED Simulations}

A total of four coupled simulations are performed (Table 1). The first is a control simulation (200 yr) after a 500-yr spinup (CM_CTRL). The external forcings (such as greenhouse gases and aerosols) are fixed at the year 2000 level. In the Southern Ocean, the shortwave absorption (net TOA shortwave radiation) bias is rather zonally symmetric (Fig. 1), motivating us to apply a zonally uniform forcing through altering the solar constant to mimic the climate impacts of the shortwave radiation bias. The first perturbed experiment is similar to CM_CTRL but with zonally uniform increased solar constant in the Southern Ocean region $\left(50^{\circ}-80^{\circ} \mathrm{S}\right)$ (CM_SO). The perturbed method is similar to Mechoso et al. (2016). For comparison, an analogous experiment is performed by increasing the solar constant over the southern tropics $\left(0^{\circ}-20^{\circ} \mathrm{S}\right)$ (CM_ST). To examine whether results are sensitive to the sign of forcing, a TOA radiative cooling experiment is carried 
TABLE 1. Description of model experiments and their corresponding PAI. Note that the standard deviation of the PAI difference between CM_SO (CM_ST) and CM_CTRL is 0.02 (0.02), estimated from every decade as a truncation. The standard deviation of PAI difference between CM_SO_COOL and CM_CTRL is 0.03 .

\begin{tabular}{|c|c|c|}
\hline Expt & Description & PAI \\
\hline CM_CTRL & A fully coupled control simulation (200 yr) after 500-yr spinup. & 0.12 \\
\hline CM_SO & $\begin{array}{l}\text { As in CM_CTRL, but with zonally uniform increased solar constant in the Southern Ocean } \\
\left(50^{\circ}-80^{\circ} \mathrm{S}\right) \text {. }\end{array}$ & 0.07 \\
\hline CM_ST & $\begin{array}{l}\text { As in CM_CTRL, but with zonally uniform increased solar constant in the southern tropics } \\
\left(20^{\circ} \mathrm{S}-0^{\circ}\right) \text {. }\end{array}$ & 0.02 \\
\hline CM_SO_COOL & $\begin{array}{l}\text { As in CM_SO, but with a TOA radiative cooling forcing in the Southern Ocean (the same } \\
\text { magnitude of forcing as CM_SO). }\end{array}$ & 0.14 \\
\hline AM_CTRL & $\begin{array}{l}\text { An AMIP control simulation ( } 20 \text { yr) forced with the climatological SST and sea ice con- } \\
\text { centration from CM_CTRL in the last } 60 \text { years. }\end{array}$ & 0.14 \\
\hline AM_SO & As in AM_CTRL, but with zonally uniform increased solar constant in the Southern Ocean. & 0.14 \\
\hline AM_ST & As in AM_CTRL, but with zonally uniform increased solar constant in the southern tropics. & 0.12 \\
\hline AM_SO_SST & $\begin{array}{l}\text { An AMIP simulation }(20 \mathrm{yr}) \text { forced with the climatological SST and sea ice from CM_SO in } \\
\text { the last } 60 \text { years (with normal insolation as AM_CTRL). }\end{array}$ & 0.09 \\
\hline AM_ST_SST & As in AM_SO_SST, but forced with the climatological SST and sea ice from CM_ST. & 0.06 \\
\hline AM_Obs_SST & An AMIP simulation forced with observed climatological SST and sea ice. & 0.30 \\
\hline
\end{tabular}

out with the same magnitude of forcing as CM_SO localized to the Southern Ocean (CM_SO_COOL). For simplicity, hereafter we use Southern Ocean (SO) and southern tropics (ST) to represent the corresponding forcing and experiments. Without the specific declaration, forcing is referring to the heating experiments. These three perturbed coupled experiments are also integrated for 200 years starting from the same initial condition as CM_CTRL.

\section{2) AMIP SIMULATIONS}

In a fully coupled system, the slowly evolving SST and the associated feedbacks make it difficult to identify the magnitude of the imposed forcing. To obtain the magnitude of the forcing, several AMIP-type simulations are carried out (Table 1). The first is a control simulation forced with the climatological SST and sea ice concentration from CM_CTRL in the last 60 years (AM_CTRL). The other two experiments are similar to AM_CTRL but with increased shortwave radiative forcing in the SO (AM_SO) and in the ST (AM_ST). Here the atmospheric model is the same as that used in coupled simulations, and the perturbations are identical to their corresponding coupled simulations where the solar constant is varied.

To assess the role of boundary conditions in controlling the ITCZ position and energy transport, two AMIP-type simulations are performed with climatological SST and sea ice forcing from CM_SO and CM_ST (the last $60 \mathrm{yr}$ ) but with normal insolation as AM_CTRL. These two experiments are referred to as AM_SO_SST and AM_ST_SST, respectively. The last AMIP experiment is carried out by holding SST and sea ice fixed to observational climatology (AM_Obs_SST).
The comparison between CM_CTRL and AM_Obs_SST shows the impacts of air-sea coupling on shaping the ITCZ. All AMIP experiments are integrated for 20 years.

\section{d. Analysis methodology}

In this study, both direct (explicit) and indirect (implicit) methods are used to obtain the AET and ocean energy transport (OET). During an equilibrium state, the total energy transport derived from the integrated net radiative flux at the TOA can be regarded as the sum of AET and OET. Here, the implicit OET can be obtained from the net surface heat flux (SFC_NET) and the AET is derived by integrating the divergence of the zonally averaged surface and TOA fluxes (e.g., Magnusdottir and Saravanan 1999). These AET and OET obtained from the indirect method are also referred to as implied AET and OET. The main purpose to show the implicit AET and OET is to verify the fidelity of the online (explicit) calculation of AET and OET.

\section{1) Budget Analysis of AET}

The atmospheric MSE can be described as $h=C_{p} T+$ $\varphi+L_{v} q_{v}+L_{f} q_{i}$, where $C_{p}$ is the specific heat of air at constant pressure, $T$ is temperature, $\varphi$ is geopotential height, $L_{v}$ is the latent heat of water vaporization, $q_{v}$ is specific humidity, $L_{f}$ is the latent heat of fusion of water, and $q_{i}$ is specific mass of ice. The MSE can also be separated into two terms: dry static energy $\left(C_{p} T+g z\right)$ and latent energy $\left(L_{v} q_{v}+L_{f} q_{i}\right)$

To identify the physical processes governing the energy transport, we decompose the time and zonal mean AET into three terms (e.g., Oort 1971): 


$$
[\overline{V h}]=[\bar{V}][\bar{h}]+\left[\overline{V^{\prime} h^{\prime}}\right]+\left[\overline{V^{*}} * \bar{h}^{*}\right],
$$

where $V$ is the mass flux $(v d p / g, v$ represents the meridional wind velocity, $d p$ is the layer thickness, and $g$ is the gravity). Square brackets indicate the zonal mean and the overbars denote the time mean. Terms with asterisks are the anomalies from the zonal mean, and terms with primes are the departure from the monthly climatology. The three terms on the right-hand side represent the contributions from the mean component, transient eddies, and stationary eddies.

Changes in AET between the perturbed and the control experiment can be approximately expressed as

$$
\begin{aligned}
\Delta[\overline{V h}] \approx & \Delta[\bar{V}][\bar{h}]_{\mathrm{CTRL}}+\Delta[\bar{h}][\bar{V}]_{\mathrm{CTRL}} \\
& +\Delta\left[\overline{V^{\prime} h^{\prime}}\right]+\Delta\left[\bar{V}^{*} \bar{h}^{*}\right],
\end{aligned}
$$

where $\Delta$ denotes the difference between perturbed and control simulations. The four terms on the right-hand side of the equation represent components from changes in mean meridional circulation (MMC), MSE, transient, and stationary eddies. These first two terms can also be referred to as the dynamic term and thermodynamic term, respectively. Note that the nonlinear product term due to the mean mass flux changes and MSE changes is relatively small and neglected here. In a simple case with equal magnitude mass flow confined to one upper and one lower layer, the vertically integrated dynamic term is determined by mean GMS, and the thermodynamic term is controlled by changes in GMS (e.g., Hill et al. 2015; Seo et al. 2017).

Following Merlis et al. (2013) and Hill et al. (2015), in the tropics, the GMS is determined by the mean circulation-related AET and the strength of the Hadley cell:

$$
\Delta h=\{[\bar{V}][\bar{h}]\} / \psi_{\max },
$$

where $\Delta h$ is the GMS, and $\psi_{\max }$ is the maximum mass flux for the Hadley cell that is a function of latitude. The braces denote the zonal and vertical integration.

\section{2) Budget AnAlysis of OET}

Different from the atmosphere, the ocean circulation has large zonal asymmetry so that the time mean OET is only separated into two components: the mean and the eddy terms (e.g., Jayne and Marotzke 2002),

$$
\overline{V m}=\bar{V} \bar{m}+\overline{V^{\prime} m^{\prime}} .
$$

The ocean energy $m$ is given by the ocean potential temperature multiplied by the heat capacity of seawater evaluated at the ocean surface (Bacon and Fofonoff
1996; Farneti and Vallis 2013), denoted by $C_{o} \theta$ ( $\theta$ is the potential temperature, and $C_{o}$ is the heat capacity of seawater per unit mass). The oceanic mass flux is defined as $\rho v d z$ ( $\rho$ is the water density, $v$ is the meridional ocean current velocity, and $d z$ is the layer thickness). Here we only consider the Eulerian advection component as the mesoscale and submesoscale eddy components have relatively weaker magnitude in the tropics.

Changes in OET between the perturbed and the control experiment can be approximately denoted as

$$
\Delta \overline{V m} \approx \Delta \bar{V} \bar{m}_{\mathrm{CTRL}}+\Delta \bar{m} \bar{V}_{\mathrm{CTRL}}+\Delta \overline{V^{\prime} m^{\prime}} .
$$

Similarly, the three terms on the right-hand side can also be referred to as the dynamic term, thermodynamic term, and the eddy term, respectively.

For both the atmosphere and ocean, we output the monthly mean of individual variables at the model level, the mass flux $V$, and the total energy transport $(V h, V m)$. This online calculation of total energy transport $(V h$, $V m$ ) is the so-called direct (explicit) calculation of AET and OET. The transient eddy term is then taken as the residual of the total and time mean terms based on Eqs. (1) and (4). The climatological monthly datasets are used for all calculations so that annual cycle related changes are included in the time mean terms.

\section{Mean state in the coupled control simulation}

Mean state biases in the control simulation may potentially impact the climate responses in perturbed experiments. We first evaluate the basic performance of the coupled control simulation (CM_CTRL). Compared to the CERES observation, this model shows a similar bias pattern of shortwave absorption with CMIP5 coupled models. In the Southern Ocean $\left(50^{\circ}-\right.$ $80^{\circ} \mathrm{S}$ ), the magnitude of bias is about $0.36 \mathrm{PW}$ for CM_CTRL and 0.54 PW for CMIP5 coupled models (Fig. 1).

Compared to GPCP, both CMIP5 and this GFDL model suffer excessive precipitation in the south tropical Pacific and south tropical Atlantic where the mean deep convection is largely absent (Figs. 1b,e). Consistently, the zonal mean precipitation bias displays a substantial meridional asymmetry with a more severe bias in the Southern Hemisphere (Figs. 1c,f). To quantify the severity of the DI problem, the precipitation asymmetry index (PAI) is adopted following Hwang and Frierson (2013). The PAI is defined by differencing the precipitation over the northern $\left(0^{\circ}-20^{\circ} \mathrm{N}, 0^{\circ}-360^{\circ}\right.$ longitude) and southern $\left(0^{\circ}-20^{\circ} \mathrm{S}, 0^{\circ}-360^{\circ}\right.$ longitude) tropics normalized by the tropical mean $\left(20^{\circ} \mathrm{S}-20^{\circ} \mathrm{N}, 0^{\circ}-360^{\circ}\right.$ longitude). The observed PAI is 0.2 for GPCP (Xiang 

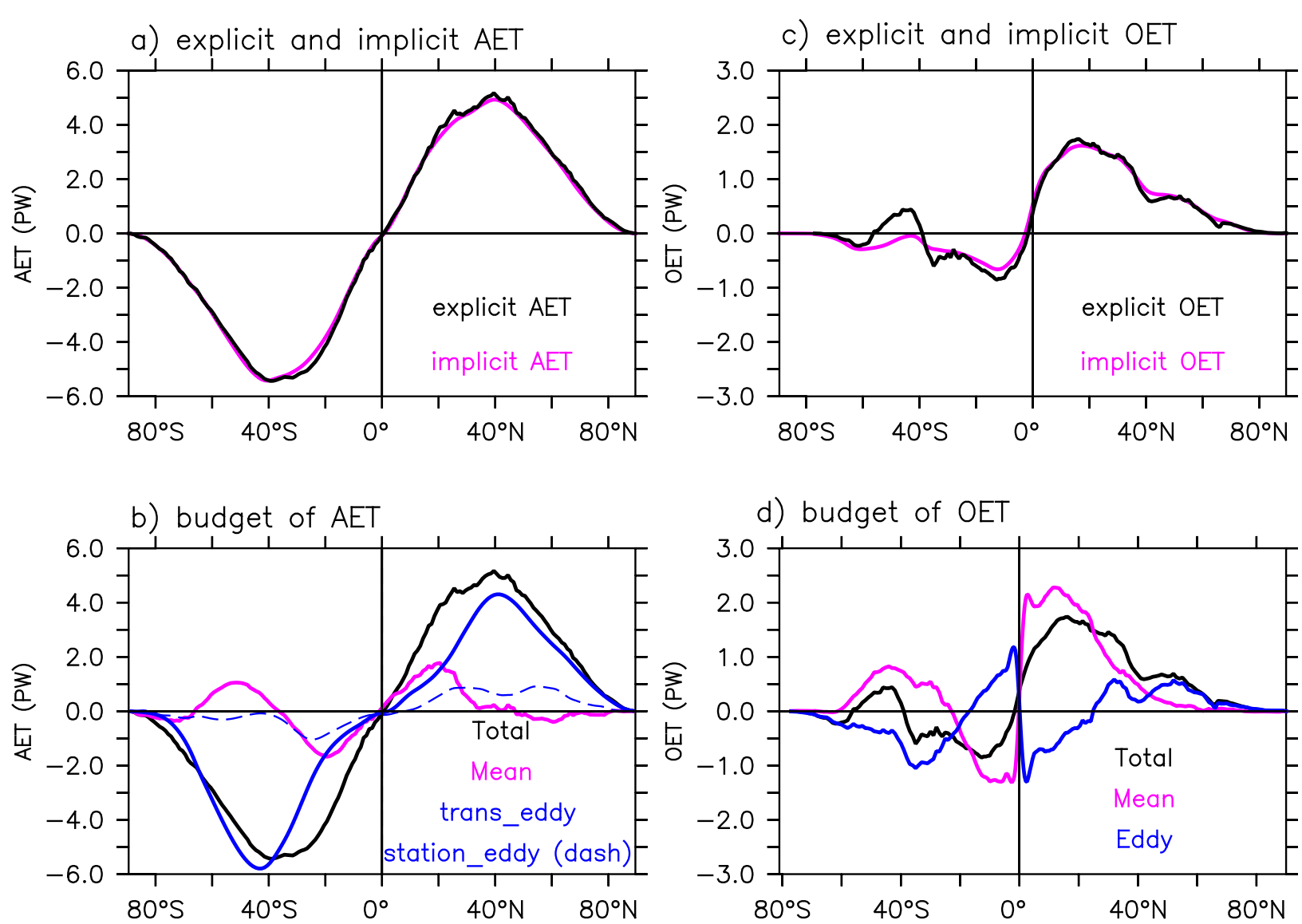

FIG. 2. (a) Annual mean AET from direct (explicit; black) and indirect (implicit; purple) calculation in the coupled control simulation (CM_CTRL). (c) As in (a), but for the OET. The implicit AET and OET are calculated based on TOA and surface fluxes. (b) The annual mean total AET (explicit; black), the AET resulting from the mean component (purple) and atmospheric transient (blue) and stationary (dashed blue) eddies. (d) The annual mean total OET (explicit; black), the OET resulting from the mean circulation (purple) and oceanic eddies (blue).

et al. 2017). A remarkable reduction of PAI from the AMIP (0.30 for AM_Obs_SST) to coupled (0.12 for CM_CTRL) simulations indicates a robust southward shift of ITCZ location and the formation of the DI problem (Table 1). A similar reduction of PAI from AMIP (0.22) to the coupled (0.05) simulation is found in the MME of CMIP5 models.

To confirm the fidelity of the methodology used to calculate the energy transport, both the implicit and explicit AET and OET are shown in Fig. 2 for CM_CTRL. The explicit (direct online) calculation of AET and OET matches reasonably well with the implicit AET and OET (Figs. 2a,c). Budget analysis is further performed. In the mid-to-high latitudes, the atmospheric transient eddy term $\left(\left[\overline{V^{\prime} h^{\prime}}\right]\right)$ dominates the total AET. Over the tropical region $\left(20^{\circ} \mathrm{S}-20^{\circ} \mathrm{N}\right)$, the atmospheric transient eddy term and the mean component $([\bar{V}][\bar{h}])$ work cooperatively to transport energy poleward (Fig. 2b).
Consistent with previous studies (Bacon and Fofonoff 1996; Farneti and Vallis 2013), the ocean tends to transport energy poleward mainly because of the mean component $(\bar{V} \bar{m})$ (Fig. 2d). In the region between $20^{\circ} \mathrm{S}$ and $20^{\circ} \mathrm{N}$, the oceanic eddy term $\left(\overline{V^{\prime} m^{\prime}}\right)$ is in the opposite direction to the mean component (Fig. 2d). In the equatorial region, the oceanic eddy component shows strong energy convergence owing to tropical instability waves (Jayne and Marotzke 2002).

The efficiency of the Hadley circulation in transporting energy strongly depends on the magnitude of mean GMS according to its definition [Eq. (3)]. Figure 3 features the annual cycle of zonally and vertically integrated AET resulting from the atmospheric mean component $([\bar{V}][\bar{h}])$, the maximum magnitude of mass flux $\left(\psi_{\max }\right)$, and mean GMS in the coupled control simulation. In the equatorial region, the AET due to the mean component varies in phase with the maximum mass flux (Fig. 3a vs Fig. 3b), and the mean GMS is 

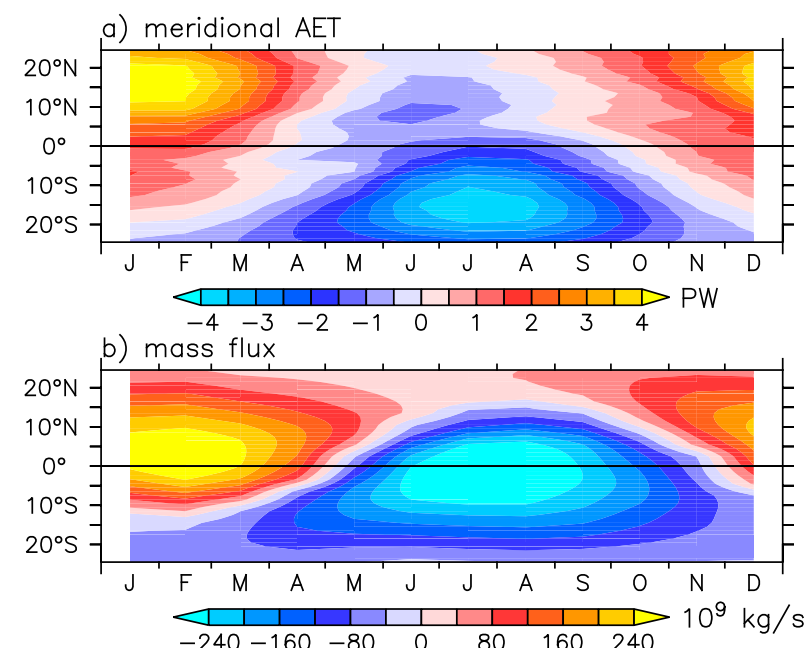
c) $\mathrm{GMS}$

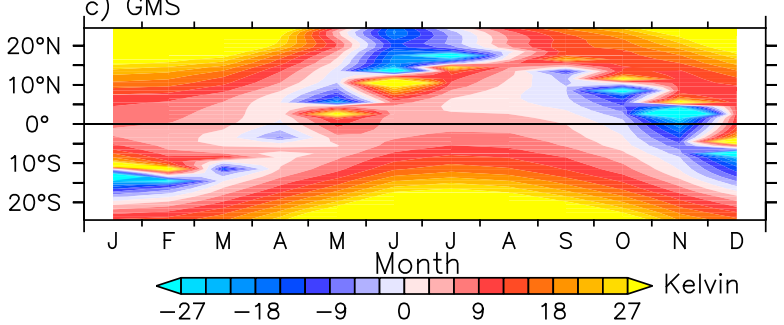

FIG. 3. Annual cycle of (a) meridional AET resulting from the atmospheric mean component, (b) the maximum mass flux streamfunction, and (c) the mean GMS (divided by $C_{p}$ to obtain units of kelvin) from the coupled control simulation (CM_CTRL).

weakly positive (the negative GMS during the transition season is largely due to the slight phase shift between the AET and mass flux) (Fig. 3c). In the equatorial region $\left(2^{\circ} \mathrm{S}-2^{\circ} \mathrm{N}\right)$, the annual mean GMS is about $2.6 \mathrm{~K}$ (Fig. 3c). Given a maximum mass flux of $20 \times 10^{9} \mathrm{~kg} \mathrm{~s}^{-1}$, the mean component-induced AET is about $0.05 \mathrm{PW}$. This is in agreement with other models showing a marginally positive GMS over the equatorial region (e.g., Held 2001; Merlis et al. 2013; Hill et al. 2015).

\section{Forcing and responses}

To ensure a qualitative comparison of coupled model responses to the prescribed forcing, we need to evaluate the magnitude of the imposed forcing from AMIP simulations without the involvement of the slowly evolving SST changes.

\section{a. Estimation of forcing magnitude}

Several AMIP simulation results are presented in Fig. 4 to identify the magnitude of the imposed forcing. Since the albedo at TOA remains nearly unchanged between the control (AM_CTRL) and the perturbed (AM_SO and AM_ST) AMIP experiments, the changes in shortwave absorption (net TOA shortwave radiation; TOA_SW) can be regarded as the actual forcing. Over the forcing domain, the shortwave absorption changes have a magnitude of 0.38 (0.36) PW for the SO (ST) forcing (Fig. 4c). This is corresponding to 4.1 (6.9) $\mathrm{W} \mathrm{m}^{-2}$ over the forcing domain for the SO (ST) forcing. The effective radiative forcing (ERF), defined as the changes in net TOA radiation (TOA_NET) after the atmospheric fast response, is another metric to measure the magnitude of the imposed forcing (e.g., Myhre et al. 2013). The ERF over the forcing domain is 0.33 (0.39) PW for the SO (ST) forcing case (Fig. 4c). Hence, the forcing is comparable between these two perturbed experiments.

\section{b. Surface temperature response}

With a similar magnitude of TOA radiative forcing, we then examine the coupled model results in the last 60 years (Fig. 5). Clearly, the global mean surface temperature response is much more sensitive to the $\mathrm{SO}$ forcing than to the ST forcing $\left(0.83^{\circ}\right.$ vs $\left.0.27^{\circ} \mathrm{C}\right)$. This contrasting sensitivity is in agreement with Kang and Xie (2014) and Rose et al. (2014) that both underlined the importance of the cloud feedbacks. Here we also found different cloud response primarily occurring between $20^{\circ}$ and $50^{\circ} \mathrm{S}$ : the SO (ST) forcing produces reduced (increased) cloud cover. One interesting difference is that Kang and Xie (2014) and Rose et al. (2014) applied forcing at the ocean surface using atmospheric models coupled to slab mixed layer ocean models in an aquaplanet configuration.

\section{c. Responses of precipitation and ITCZ position}

For both experiments, precipitation increases (decreases) to the south (north) of the equator, reminiscent of a DI-like pattern (Figs. 5 and 6). But, the magnitude is significantly stronger in the ST forcing than the SO forcing. This concurs with Xiang et al. (2017) who argued that the biases of TOA and surface fluxes in the tropics are more critical in driving the DI problem than that in the extratropics. In addition, for the SO forcing, the equatorial Pacific features enhanced precipitation anchored by more surface warming in the equatorial central-eastern equatorial Pacific, while this is absent in the ST forcing (Fig. 5).

The PAI is about 0.07 and 0.02 for CM_SO and CM_ST, respectively (Table 1). They differ significantly with CM_CTRL with the magnitude differences of $-0.05 \pm 0.02$ and $-0.10 \pm 0.02$ (Table 1 ). Thus, the ITCZ shift is more sensitive to the ST forcing than to the SO forcing. This conclusion remains valid when normalized by their corresponding net TOA shortwave radiative forcing and also the ERF. In the next section, 

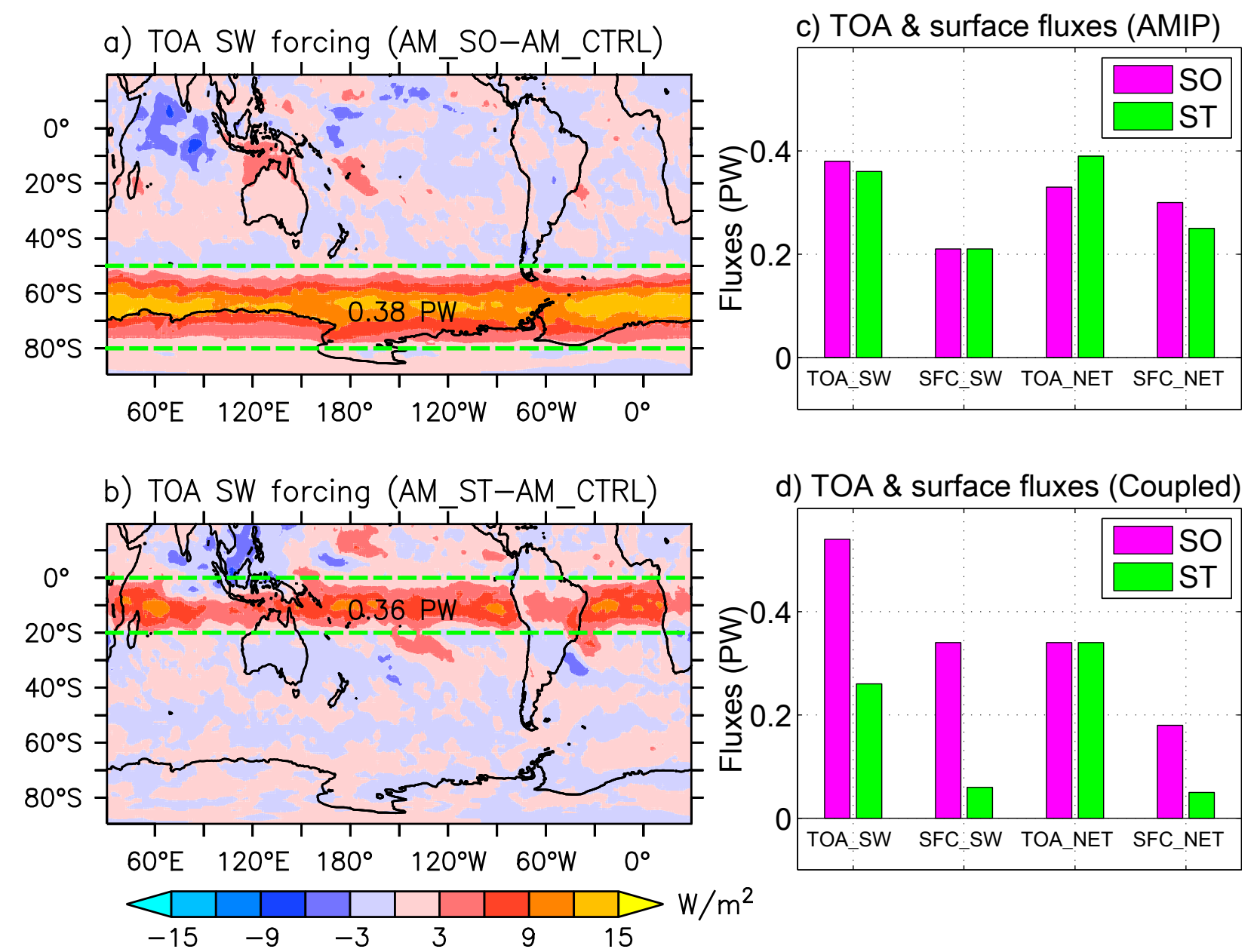

d) TOA \& surface fluxes (Coupled)

FIG. 4. (a) The shortwave absorption changes associated with the SO radiative forcing estimated from the AMIP simulations (AM_SO - AM_CTRL). The green dashed lines show the region with the prescribed forcing. (b) As in (a), but for the ST radiative forcing (AM_ST - AM_CTRL). (c) The TOA and surface flux changes in the SO domain $\left(50^{\circ}-80^{\circ} \mathrm{S}\right.$; purple) and the ST domain $\left(20^{\circ} \mathrm{S}-0^{\circ}\right.$; green) for these two different forcing: TOA_SW, SFC_SW, TOA_NET, and SFC_NET. (d) As in (c), but for coupled simulations during the last 60 years. Positive denotes downward fluxes for both TOA and surface fluxes. Note that the AMIP-type simulations give the better estimate of the initial forcing strength.

particular emphasis is placed on understanding the physical processes leading to such a strong contrast in the tropical precipitation response.

\section{ITCZ shift, energy transport, and SST forcing}

Based on the energetic constraint theory, the crossequatorial AET was found to exhibit a coherent variation with the ITCZ migration. The cross-equatorial AET has been used to explain the observational annual cycle of ITCZ, ITCZ changes in paleoclimate, and ITCZ biases in current climate models (e.g., Schneider et al. 2014; Donohoe et al. 2013; Hwang and Frierson 2013; McGee et al. 2014). For the coupled control simulation (CM_CTRL), the annual cycle of ITCZ shift is also well correlated with the cross-equatorial AET (not shown). Insight into mechanisms leading to the ITCZ shift may be gained by exploring the corresponding energy transport for these two perturbed experiments.

\section{a. Changes in implicit AET and OET}

First, we present the responses in the implicit AET and OET in Fig. 6. With the SO radiative forcing, the total energy transport (the sum of the implicit AET and OET) gradually decays northward from around $50^{\circ} \mathrm{S}$, with most of the imposed energy transported northward across the equator (Fig. 6a). It is indicative of a weak TOA radiative dampening effect in the Southern Hemisphere. Overall, the atmosphere and ocean play an equivalent role in transporting the imposed energy for the SO forcing (Fig. 6a). 

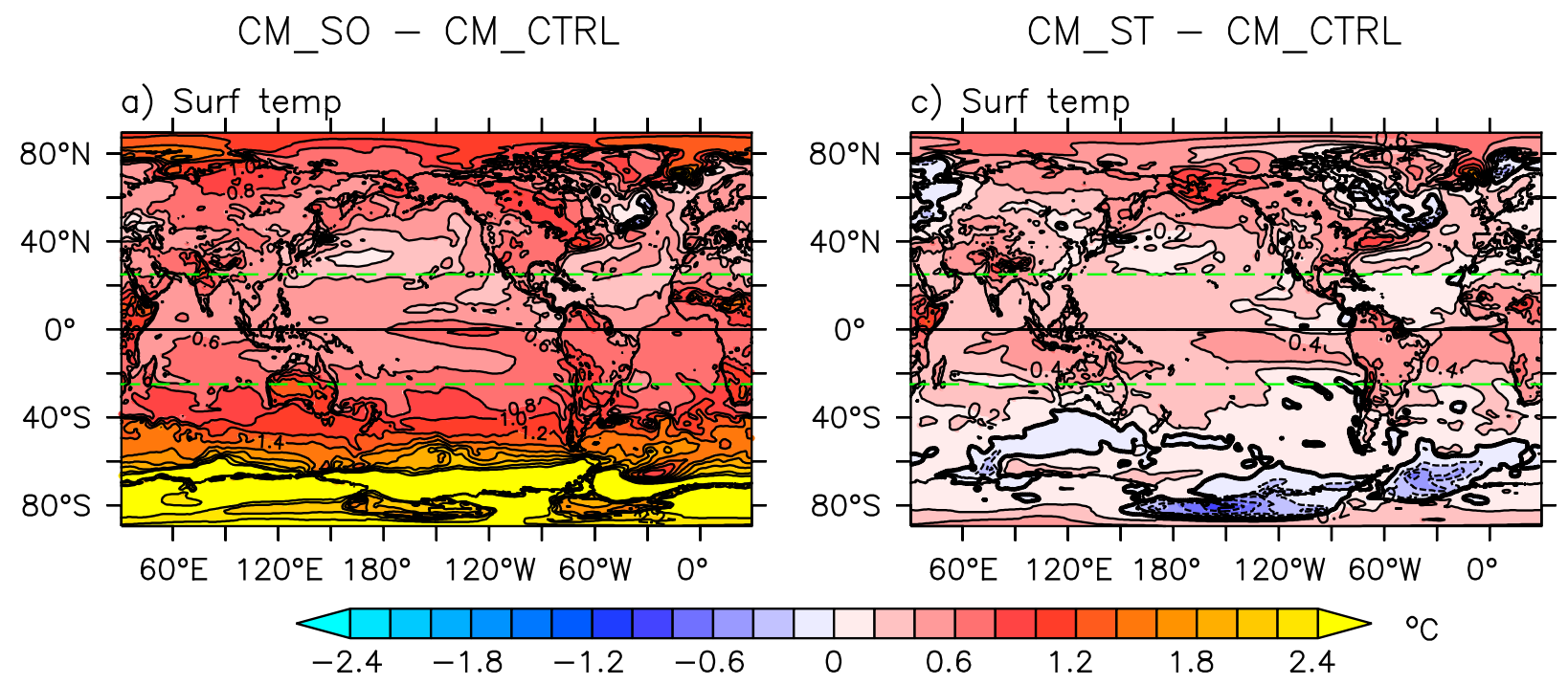

b) Prep \& wind stress

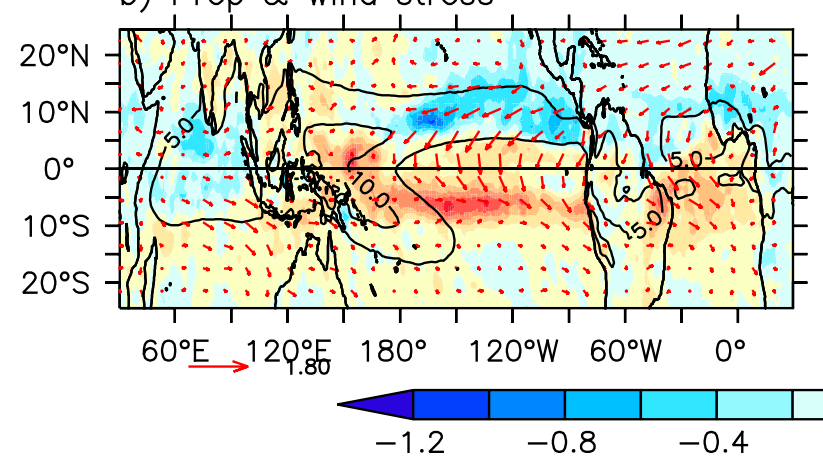

d) Prep \& wind stress

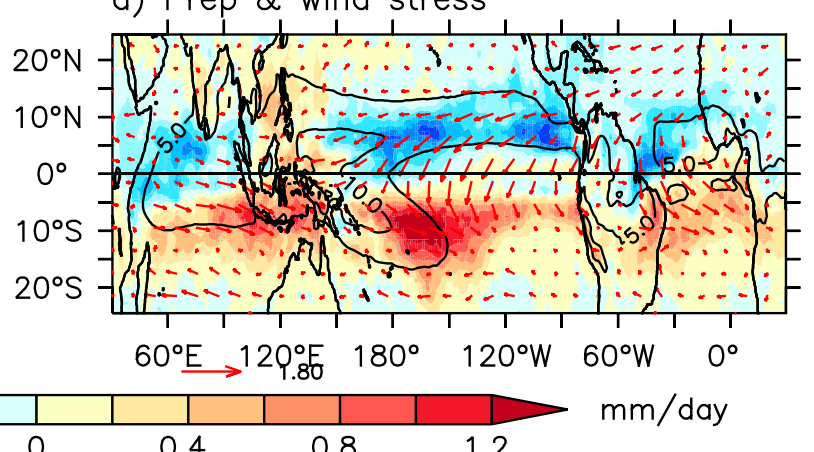

FIG. 5. Changes in annual mean (a) surface temperature and (b) precipitation (shading) and 925-hPa wind (vectors; $\mathrm{m} \mathrm{s}^{-1}$ ) associated with the SO radiative forcing (CM_SO - CM_CTRL). The green dashed lines in (a) show the domain for (b). Contours in (b) denote the climatological precipitation in the coupled control simulation $\left(\mathrm{mm} \mathrm{day}^{-1}\right)$. (c),(d) As in (a),(b), but for the ST forcing (CM_ST CM_CTRL).

For the ST forcing, the total energy transport exhibits both northward (crossing the equator) and southward (crossing $20^{\circ} \mathrm{S}$ ) transport (Fig. 6b). This is distinguished from the SO forcing with almost no southward energy transport. Interestingly, the implicit OET response is overall very weak, and nearly all of the imposed energy is transported by the atmosphere (Fig. 6b). Within the equatorial region $\left(2^{\circ} \mathrm{S}-2^{\circ} \mathrm{N}\right)$, the AET explains about $44 \%(91 \%)$ of the total energy transport for the SO (ST) forcing.

The above results suggest that the partitioning of energy transport between the atmosphere and ocean depends on the forcing latitudes: for the higher-latitude forcing, the ocean is more effectively transporting the imposed energy than the atmosphere, and vice versa. In sections $5 b$ and $5 c$, we explore the processes and mechanisms accounting for the contrasting OET and AET responses.

\section{b. Understanding the changes in $O E T$}

Why do the changes in OET show latitudinal dependence on the forcing location (Fig. 6)? We address this question from both the atmospheric and the oceanic perspectives.

Over the forcing domain, the ocean heat uptake is different between these two cases. With nearly identical changes in net TOA radiation for these two cases (0.34 vs $0.34 \mathrm{PW}$ ), the SO forcing shows more energy penetrating into the underlying ocean (more ocean heat uptake) than the ST forcing by comparing the net surface heat flux (0.18 vs $0.05 \mathrm{PW}$ ) (Fig. 4d). The reasons are threefold. First, the SO forcing reduces cloud cover and sea ice concentration locally, resulting in increased shortwave absorption. This effect is evident by comparing the difference of between the coupled and AMIP simulation results (Figs. 4c,d). In contrast, the ST forcing increases local convection that reduces both the outgoing 

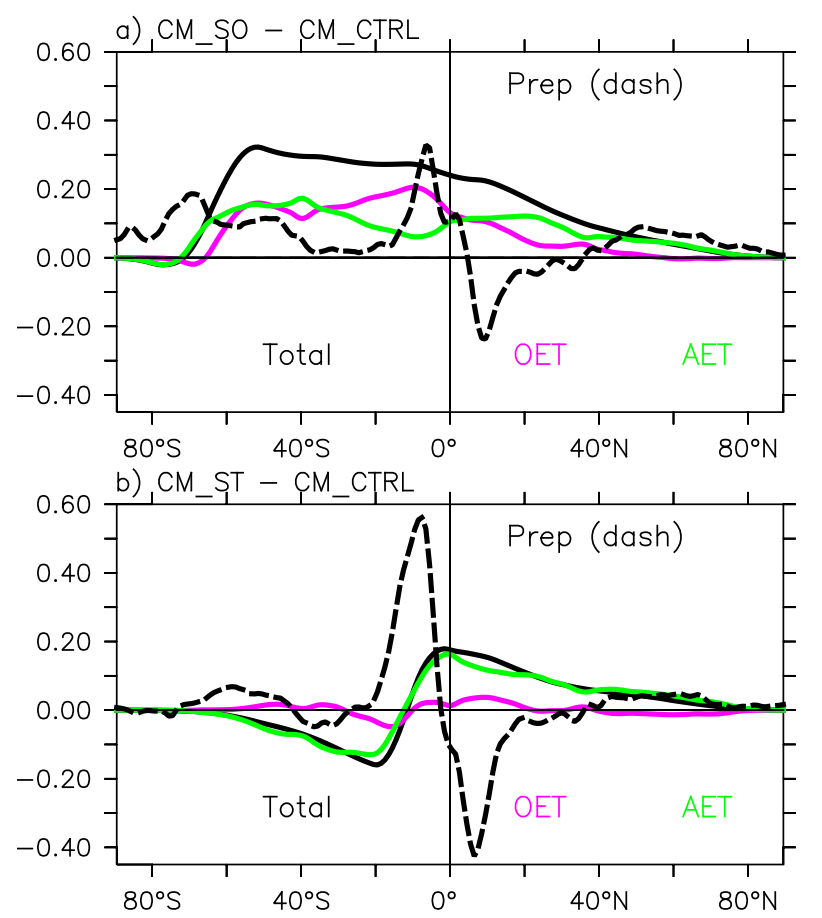

FIG. 6. Changes in annual mean meridional OET (implicit; purple), AET (implicit; green), and the total energy transport (the sum of AET and OET; black) associated with the (a) SO (CM_SO - CM_CTRL) and (b) ST (CM_ST - CM_CTRL) radiative forcing (PW). The dashed black lines are the corresponding zonal mean precipitation changes $\left(\mathrm{mm} \mathrm{day}^{-1}\right)$.

longwave radiation (OLR) and shortwave absorption. Compared to its AMIP simulation (AM_ST), less energy penetrates into the ocean for the ST forcing. Second, the atmospheric absorption of the shortwave radiation [the difference between shortwave absorption and the net surface shortwave radiation (SFC_SW)] differs dramatically: $37 \%$ versus $77 \%$ for the SO and ST forcing (Fig. 4d). This is likely due to the difference in mean moisture between the tropics and the high latitudes. Third, it is easier for the ocean to take up heat in the SO because of the mean downward motion at $50^{\circ}-60^{\circ} \mathrm{S}$ associated with the mean meridional overturning circulation (MOC; see Fig. 8b) (e.g., Frey et al. 2017). For the ST forcing, the peak insolation anomaly occurs in a location where there is neither net downward nor upward ocean circulation. The ocean thus cannot take the heat to depth as easily in the ST simulation as in the SO simulation.

To further understand the contrasting OET changes, the oceanic energy budget analysis is further performed (Fig. 7). For both cases, changes in the equatorial OET are primarily attributed to the dynamic term because of ocean circulation changes $(\sim 0.25 \mathrm{PW})$. This is cohesive with similar ocean circulation changes
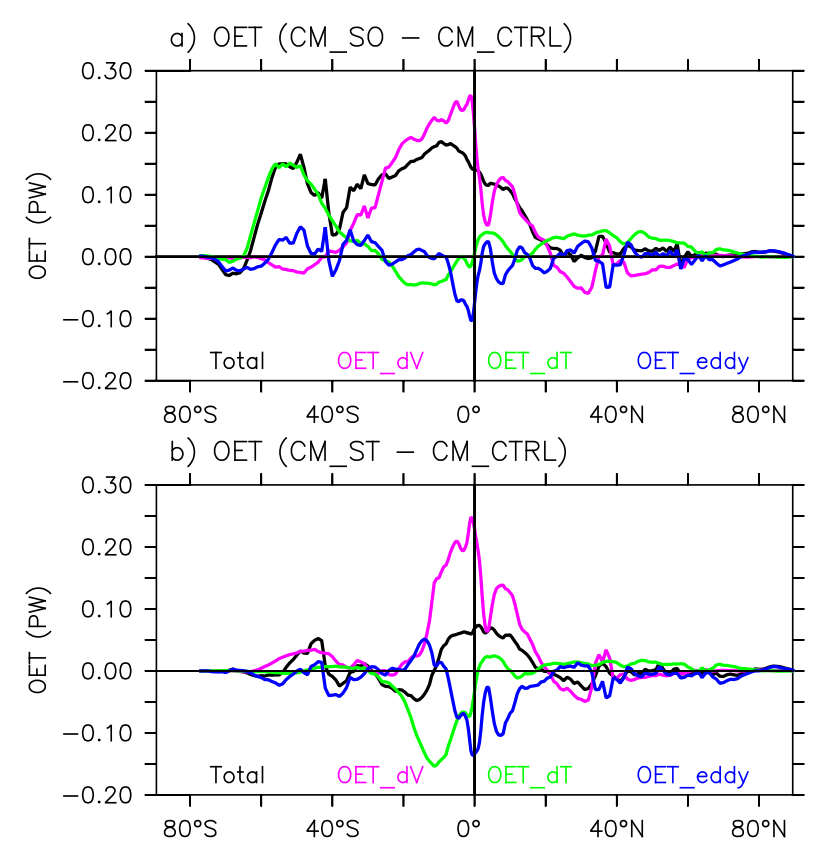

FIG. 7. (a) The total OET changes (black) with the SO forcing (CM_SO - CM_CTRL), and the individual terms: the dynamic term (purple), the thermodynamic term (green), and oceanic eddy term (blue). (b) As in (a), but for the ST forcing. All these are from the explicit calculation of energy transport.

over the tropics, characterized by anomalously clockwise circulation in the upper ocean (Figs. 8a,c). Strikingly, an anomalously anticlockwise circulation is formed in the deeper ocean (below $1000 \mathrm{~m}$ ) for the SO case only (Fig. 8a), contributing to transport energy southward.

The contrast in the total OET response is mainly attributed to the thermodynamic (potential temperature changes) term and oceanic eddy term (Fig. 7). For the ST forcing, these two terms almost completely compensate for the dynamic term in the equatorial region, resulting in a weak total OET response (Fig. 7b). For the SO forcing, these two terms are dramatically weaker, resulting in a much stronger total OET changes than the ST forcing (Fig. 7a).

Investigation of ocean temperature changes is instrumental in explaining the changes in the thermodynamic and eddy terms. Intriguingly, the ST forcing drives a considerable subsurface cooling $\left(\sim-0.6^{\circ} \mathrm{C}\right)$ in the southern tropics, which is nearly absent in the SO forcing experiment (Fig. 8d vs Fig. 8b). With the aid of mean ocean circulation characterized by poleward transport in the upper ocean and equatorward transport at the subsurface, the salient subsurface cooling together with the surface warming gives rise to a southward OET for the ST forcing case (Fig. 8d). For the ST forcing, the prominent subsurface meridional temperature gradient 


\section{CM_SO - CM_CTRL}

a) anomalous MOC \& mean temp

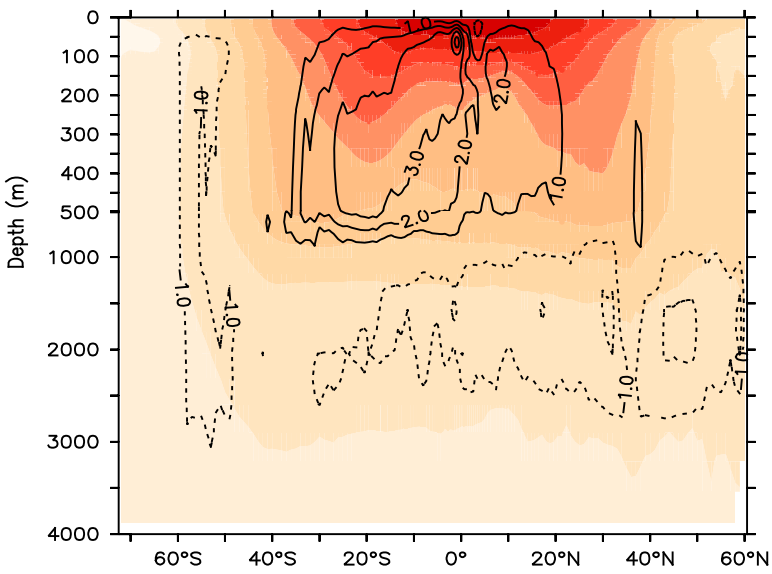

b) anomalous temp \& mean MOC

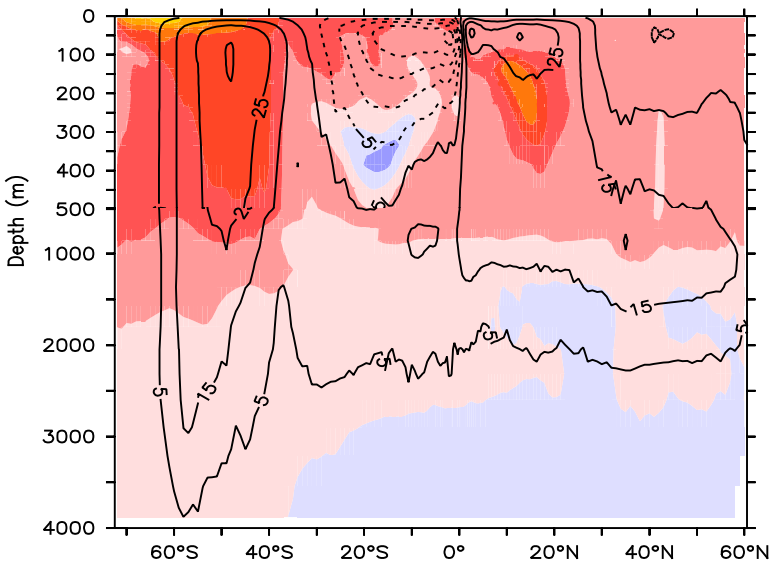

CM_ST - CM_CTRL

c) anomalous MOC \& mean temp

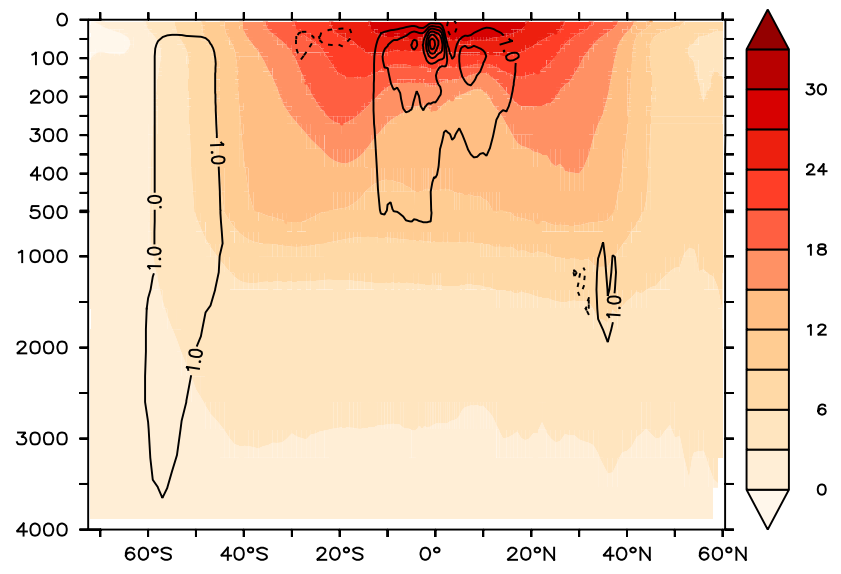

d) anomalous temp \& mean MOC

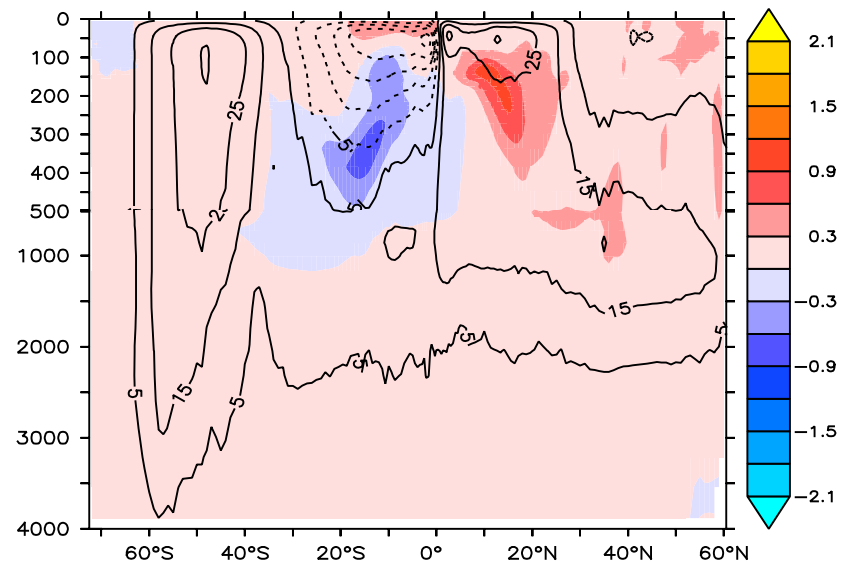

FIG. 8. (a) Zonal and annual mean ocean temperature in the coupled control simulation (shading; ${ }^{\circ} \mathrm{C}$ ), and changes in annual mean ocean MOC streamfunction with the SO forcing (contours; $\mathrm{Sv}, 1 \mathrm{~Sv} \equiv 10^{9} \mathrm{~kg} \mathrm{~s}^{-1}$ ). The clockwise circulation is in solid contours, and the anticlockwise circulation is in dashed contours. (b) The changes in zonal and annual mean temperature (shading; ${ }^{\circ} \mathrm{C}$ ) with the SO forcing and the mean MOC in CM_CTRL (contours; Sv). (c),(d) As in (a),(b), but for the ST forcing.

also facilitates the development of oceanic eddies based on a downgradient eddy closure, leading to the southward eddy-driven OET (Fig. 7b).

We further argue that the meridional scale of the ocean circulation holds the key to explaining the changes in ocean temperature and the OET. For the ST forcing, the anomalous circulation has a much smaller meridional scale (around $15^{\circ} \mathrm{S}-15^{\circ} \mathrm{N}$ ) (Fig. $8 \mathrm{c}$ ) than that due to the SO forcing (around $35^{\circ} \mathrm{S}-20^{\circ} \mathrm{N}$ ) (Fig. 8a). As one rising limb of the anomalous MOC, the anomalous upwelling largely accounts for the subsurface cooling in the southern tropical region for the ST forcing. For the SO forcing, the anomalous upwelling in the high latitudes does not lead to considerable temperature changes because of the weak vertical mean temperature gradient (Figs. 8a,b). The ocean circulation changes are further traced back to the dynamic wind forcing, which will be discussed later.

\section{c. Understanding the changes in AET}

The atmospheric energy budget analysis is performed to understand the contrasting AET changes (Fig. 9). For the SO forcing, changes in annual mean AET are dominated by the atmospheric transient eddy term in the mid-to-high latitudes. Over the equatorial region, the GMS change term and the transient eddy term are two dominant terms contributing to the northward cross-equatorial AET changes for both cases (Figs. 9a,b). The changes in stationary eddies are overall weak. Interestingly, for both cases the dynamic term (from mean circulation changes) does not transport energy northward near the equatorial region given a positive mean 
a) AET (CM_SO - CM_CTRL)

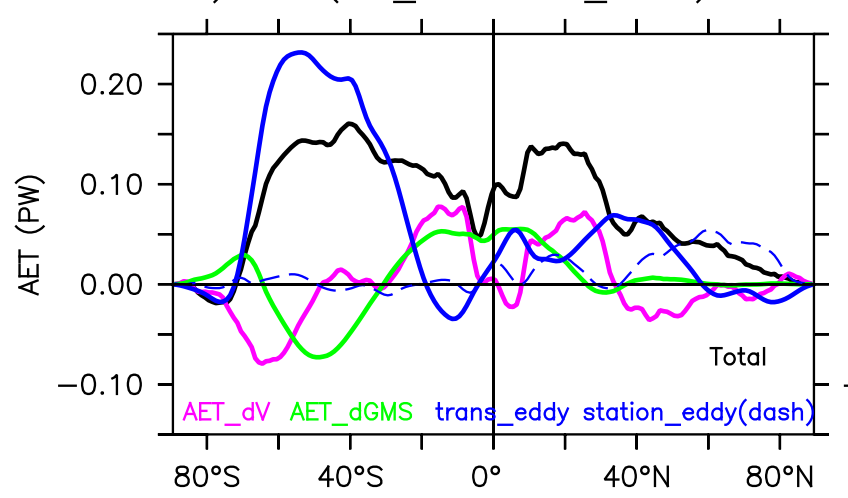

b) AET (SST effect from SO forcing)

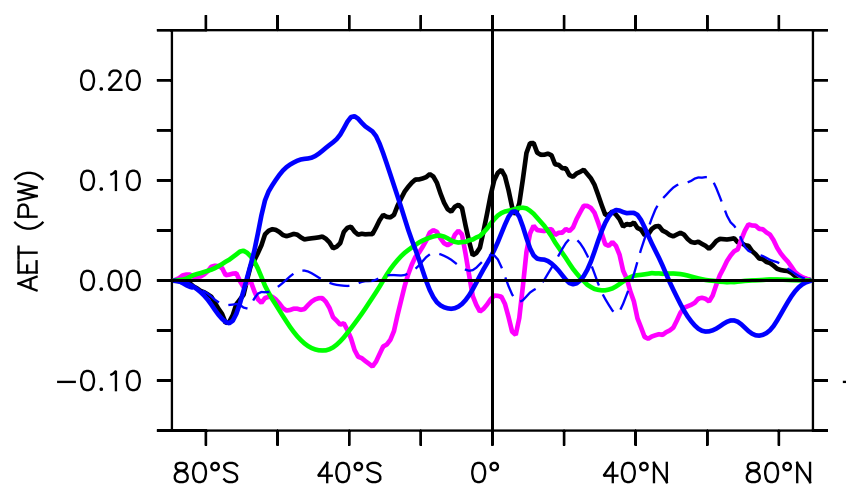

c) AET (CM_ST - CM_CTRL)

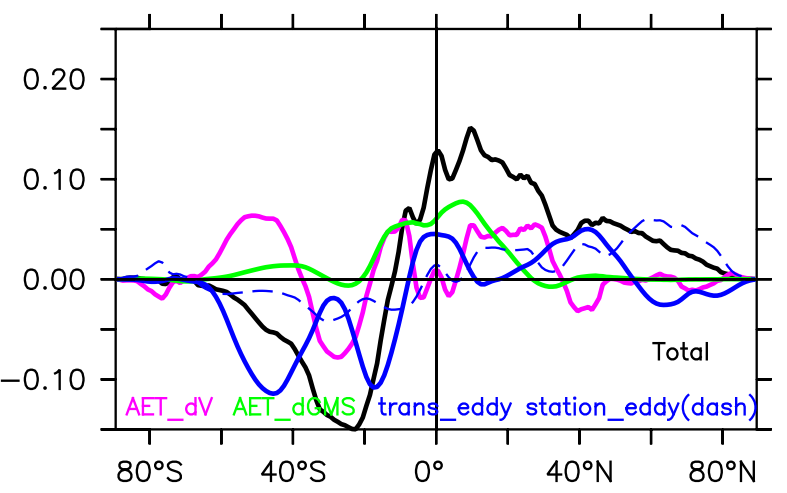

d) AET (SST effect from ST forcing)

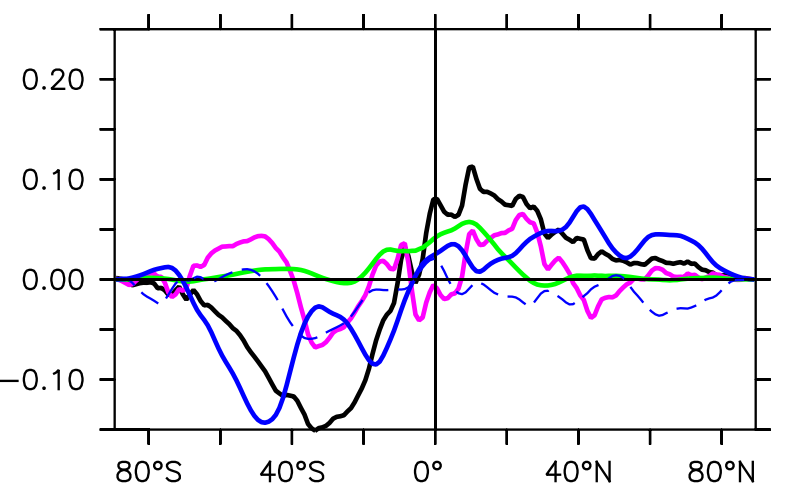

FIG. 9. (a) The total AET changes (black) with the SO forcing (CM_SO - CM_CTRL), and the individual components: the dynamic term (purple), thermodynamic term (green), transient eddy term (blue), and stationary eddy term (dashed blue). (b) As in (a), but from AMIP-type simulations only resulting from the boundary layer SST changes associated with the SO forcing together with normal insolation (AM_SO_SST - AM_CTRL). (c),(d) As in (a),(b), but for the ST forcing. All these are from the explicit calculation of energy transport.

GMS (Figs. 9a,b). How can this happen? Whether the ITCZ shift can be linked to the equatorial GMS change term is also a question. We will explore these questions in section $5 \mathrm{~d}$ by focusing on the seasonality of the ITCZ shift and energy transport as the annual mean results may potentially obscure the causality.

\section{d. Seasonality of ITCZ shift and energy transport}

For these two cases, changes in zonal mean precipitation resemble a strikingly similar seasonality with a stronger response during boreal winter and spring than the other two seasons (Figs. 10b,e), albeit a distinctly different seasonality of the imposed forcing (Figs. 10a,d). It implies that the precipitation response is strongly modulated or anchored by the background mean state, which has been demonstrated over some regions, such as the tropical Indian Ocean (e.g., Xiang et al. 2011) and the western North Pacific (e.g., Xiang et al. 2013). As a good proxy of ITCZ migration, the seasonality of PAI changes (Figs. 10c,f) follows that of the anomalous ITCZ shift (Figs. 10b,e). For both cases, changes in the equatorial
OET display much more intense seasonality than the AET. The annual cycle of the OET changes is highly correlated with that of PAI changes (Figs. 10c,f), and we claim that the equatorial OET is strongly coupled to the ITCZ migration through the zonal wind forcing (Figs. 10b,e). Nevertheless, the annual cycle of PAI changes does not follow the changes in cross-equatorial AET (Figs. 10c,f). For instance, for the SO forcing, strong anomalous northward crossequatorial AET appears during July-November when PAI remains nearly unchanged (Fig. 10c).

We did a further budget analysis of the crossequatorial AET (Fig. 11). For the SO forcing case, the annual cycle of the total cross-equatorial AET response closely follows the GMS change term (Fig. 11a). The importance of GMS change in controlling the ITCZ shift has also been stressed in Seo et al. (2017). The GMS change term has a nearly opposite sign to the crossequatorial AET due to the mean component in the control simulation (Fig. 11a vs Fig. 3a). It suggests that the mean GMS is reduced in the SO forcing experiment, associated with relatively more MSE in the lower 
SO forcing

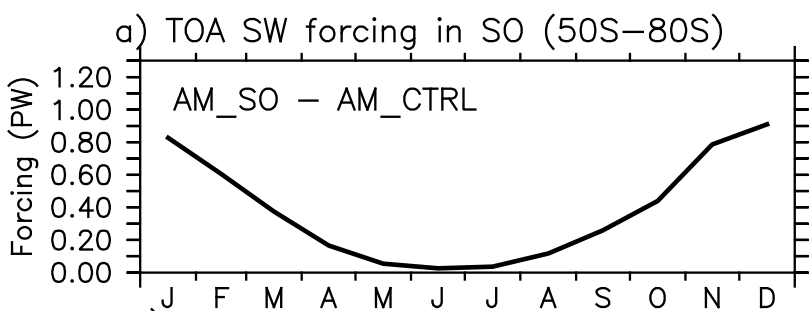

b) prep change
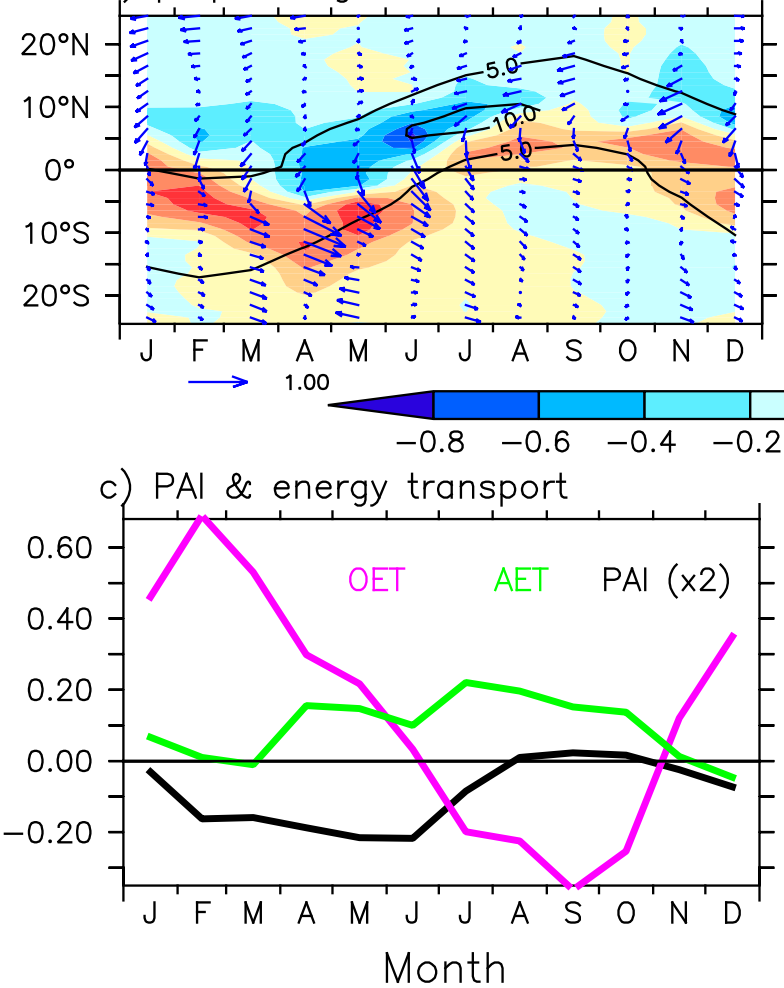

ST forcing

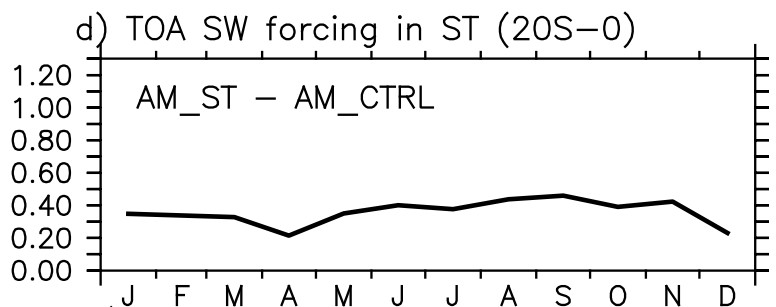

e) prep change
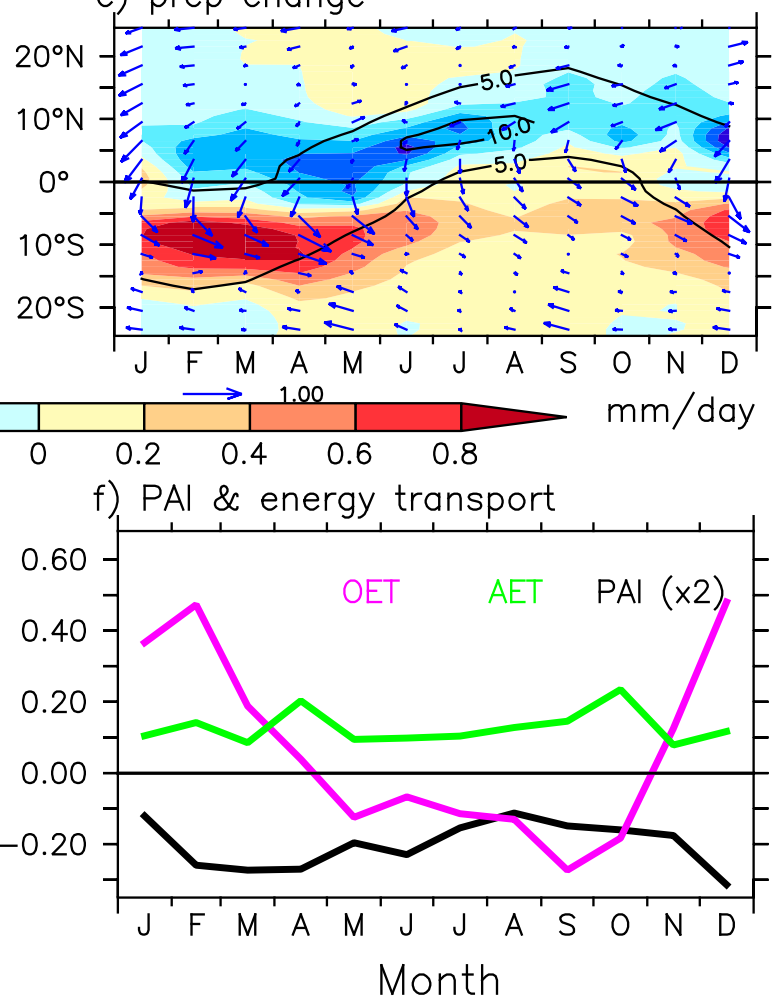

FIG. 10. (a) Annual cycle of net TOA shortwave radiative forcing (shortwave absorption changes) over the SO $\left(50^{\circ}-80^{\circ} \mathrm{S}\right)$ estimated from the AMIP results (AM_SO - AM_CTRL). (b) Changes in annual cycle of zonal mean precipitation (shading; mm day ${ }^{-1}$ ) and 925-hPa wind (vectors; $\mathrm{m} \mathrm{s}^{-1}$ ) associated with the SO forcing (CM_SO - CM_CTRL). The contours show the annual cycle of zonal mean precipitation in the coupled control simulation $\left(\mathrm{mm} \mathrm{day}^{-1}\right)$. (c) Changes in annual cycle of PAI (multiplied by 2; black), the equatorial $\left(2^{\circ} \mathrm{S}-2^{\circ} \mathrm{N}\right)$ explicit OET (purple; PW), and the explicit AET (green; PW) resulting from the SO forcing in coupled simulations. (d)-(f) As in (a)-(c), but for the ST forcing.

troposphere than that in the upper troposphere. For the ST forcing, the mean GMS is inferred to increase in boreal winter but decrease in boreal summer considering its seasonal variation (Fig. 11b). For both cases, the GMS change term has a distinctly different seasonality with the anomalous ITCZ shift, implying that the GMS change may not be the root cause for the anomalous ITCZ shift (Fig. 11).

The transient eddy term varies coherently with the PAI changes and dominates changes in the total crossequatorial AET during December-May (Fig. 11). Is there a connection between the ITCZ shift and atmospheric eddies? Peters et al. (2008) pointed out that there exists a relationship between atmospheric eddies and mean circulation: larger eddy export of MSE is linked to a shallower mean circulation. A shallower mean circulation typically represents a weaker GMS considering the vertical profile of mean MSE over the tropics. Here, we speculate that the transient eddy energy flux acts as a consequence of the ITCZ shift, through the establishment of an anomalous meridional MSE gradient based on a downgradient eddy closure.

Strikingly, the dynamic term even induces a southward cross-equatorial AET during December-May (Fig. 11) despite a positive mean GMS in the equatorial region (Fig. 3c). This is related to the vertical profile of the Hadley circulation. For both cases, the anomalous 

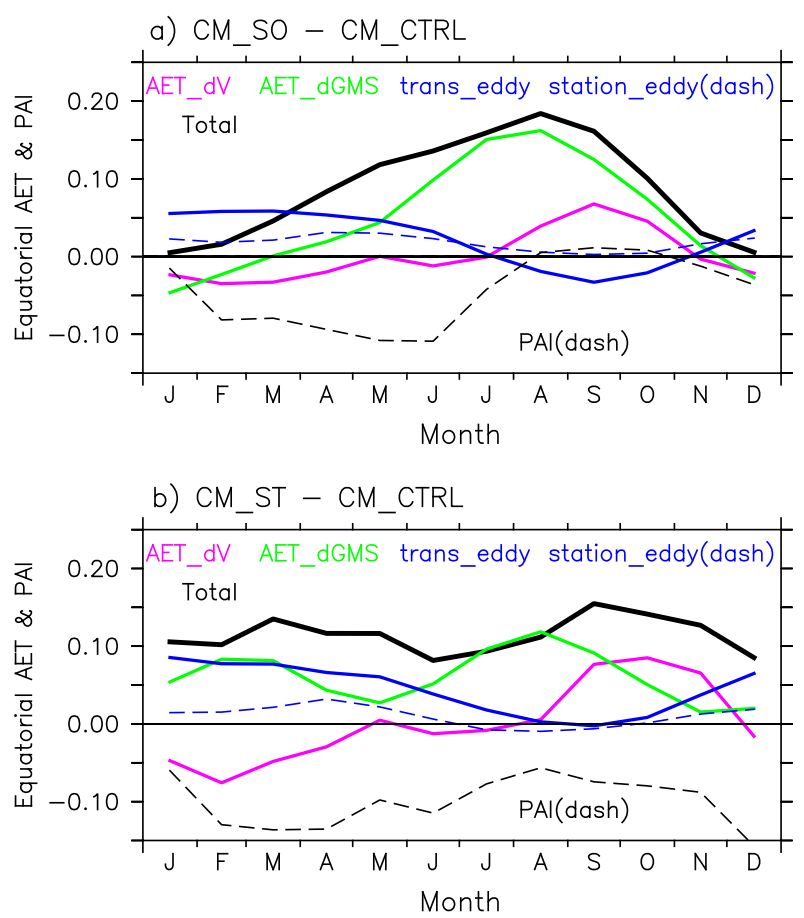

FIG. 11. (a) Changes in annual cycle of equatorial $\left(2^{\circ} \mathrm{S}-2^{\circ} \mathrm{N}\right)$ AET (PW) associated with the SO forcing, and its individual components: the dynamic term (purple), thermodynamic term (green), transient eddy term (blue), and stationary eddy term (dashed blue). A 3-month running mean is applied here. (b) As in (a), but for the ST forcing. All these are from the explicit calculation of energy transport. The corresponding PAI changes are shown in black dashed lines.

southward equatorial $\left(2^{\circ} \mathrm{S}-2^{\circ} \mathrm{N}\right)$ return flow is confined within the boundary layer (below $850 \mathrm{hPa}$ ), while the return flow in CM_CTRL appears between 600 and $1000 \mathrm{hPa}$ (Fig. 12c). Given the large vertical gradient of the mean MSE (Fig. 12d), such a wind profile difference can readily explain the lower efficiency of the anomalous circulation in transporting energy than the mean component in the coupled control simulation. This is probably related to the precipitation change pattern primarily over the regions without active deep convection (Figs. 5b,d). One interesting feature is that the anomalous Hadley cell shows a much smaller meridional scale (between $10^{\circ} \mathrm{S}$ and $10^{\circ} \mathrm{N}$ ) than the coupled control simulation (Figs. 12a,b).

\section{e. Role of boundary layer SST pattern in determining ITCZ position}

The above evidence shows some difficulty explaining the migration of ITCZ position using the traditional energetic constraint framework. In other words, changes in AET do not necessitate altering the ITCZ position and the Hadley circulation. To further understand the contrasting precipitation changes (Figs. 5 and 6), we carried out a budget analysis of the latent energy transport during December-May (Fig. 13). For the SO forcing, both the dynamic term (anomalous meridional wind convergence of mean moisture) and the moisture change term (mean meridional wind convergence of anomalous moisture) are important in converging latent energy in the southern tropics (Fig. 13a). For the ST forcing, the dynamic term is the dominant term and is much stronger than that in the SO forcing (Fig. 13b). Therefore, the anomalous meridional wind difference is essential in explaining the more sensitive ITCZ response in the ST forcing than the SO forcing.

The boundary layer meridional wind changes are tied to the SST changes. For the ST forcing, the anomalous SST shows a prominent meridional gradient on its north and south flanks that drives winds and moisture convergence from both sides, conducive to produce strong precipitation changes (Fig. 13b). In contrast, the SO forcing has much weaker meridional SST gradient over the equatorial region (Fig. 13a). The different SST pattern is most evident in the Pacific basin (Figs. 5a,c). Note that the anomalous return flow primarily occurs in the atmospheric boundary layer for both experiments (Fig. 12c). It provides indirect evidence that the anomalous Hadley circulation is forced by the SST changes. These results are consistent with previous studies underlining the essential role of SST gradient in driving boundary moisture convergence and tropical precipitation (Lindzen and Nigam 1987; Back and Bretherton 2009).

To further confirm this hypothesis, two AMIP simulations (AM_SO_SST and AM_ST_SST) are conducted with SST and sea ice forcing from CM_SO and CM_ST but with normal insolation as in AM_CTRL (Table 1). For both cases, the AMIP simulations well reproduce the zonal mean precipitation changes in their coupled simulations (Figs. 14a,c). Note that the SO forcing produces a stronger response in tropical mean SST but a weaker ITCZ response than the ST forcing (Fig. 5). It corroborates that the SST pattern is essential in driving the tropical precipitation changes. Meanwhile, the total and the individual component of AET changes are also reasonably represented in these AMIP simulations (Fig. 9). It sheds light on the importance of SST in redistributing the imposed energy. Here it is assumed that the difference in sea ice concentration has a weak impact on the contrasting precipitation changes.

These AMIP simulations also well reproduce the zonal mean zonal wind stress response from the coupled simulation results (Figs. 14b,d), supporting the fact that changes in zonal wind stress are predominately governed by SST changes (Lindzen and Nigam 1987). These 

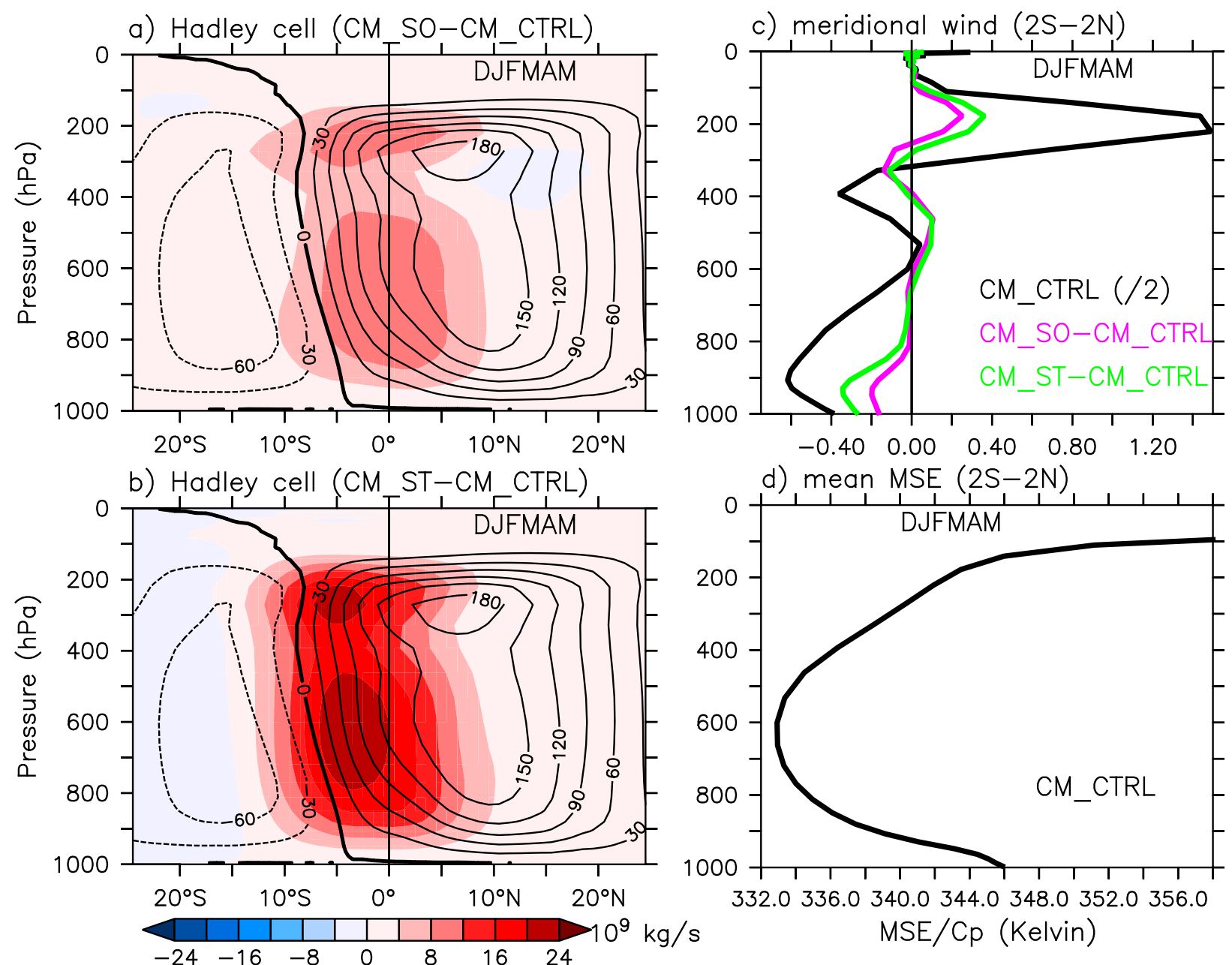

d) mean MSE $(2 S-2 N)$

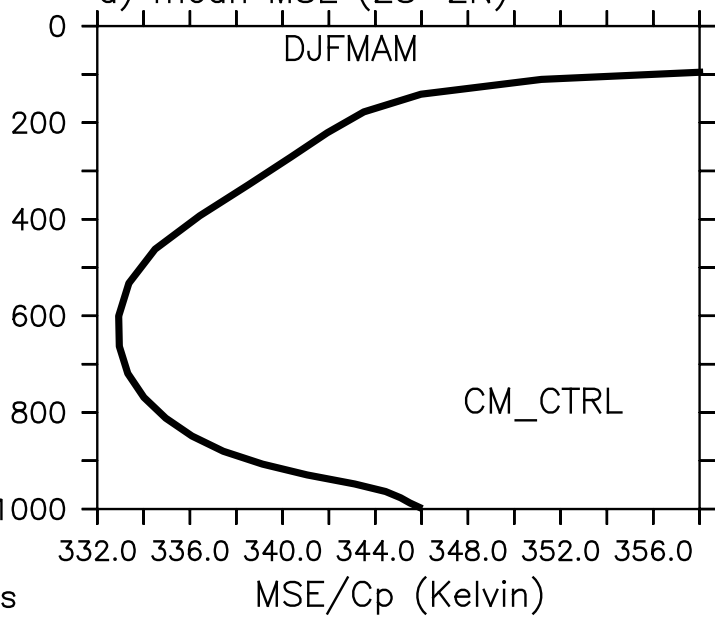

FIG. 12. Changes in atmospheric meridional mass flux resulting from the (a) SO forcing and (b) ST forcing (shading). Contours are the mean meridional mass flux in the coupled control simulation $\left(10^{9} \mathrm{~kg} \mathrm{~s}^{-1}\right)$. (c) Zonal mean meridional winds in the coupled control simulation (divided by 2; black), changes in zonal mean meridional winds with the SO forcing (purple), and the ST forcing (green). The meridional winds $\left(\mathrm{m} \mathrm{s}^{-1}\right)$ are averaged over the equatorial region $\left(2^{\circ} \mathrm{S}-2^{\circ} \mathrm{N}\right)$. (d) Vertical profile of mean MSE (divided by $\left.C_{p}\right)$ over the equatorial region $\left(2^{\circ} \mathrm{S}-\right.$ $2^{\circ} \mathrm{N}$ ) from the coupled control simulation. All results are during December-May when the ITCZ response is most pronounced.

zonal wind stress changes are essential in driving the changes in ocean circulation, temperature, and the OET. For both cases, changes in zonal wind stress are similar over the region between $15^{\circ} \mathrm{S}$ and $15^{\circ} \mathrm{N}$, characterized by the westerly (easterly) wind stress anomaly in the Southern (Northern) Hemisphere. This wind stress pattern is able to drive a northward upper-ocean flow via the Ekman transport (Figs. 8a,c). A salient difference is apparent between $15^{\circ}$ and $30^{\circ} \mathrm{S}$ where the ST (SO) forcing has an overall strengthened (slackened) zonal wind stress (Figs. 14b,d). For the ST forcing, a prominent negative wind stress curl between $8^{\circ}$ and $27^{\circ} \mathrm{S}$ drives the cold subsurface temperature by means of the Ekman pumping effect. Therefore, changes in SST are important in determining the zonal wind stress and thus the OET changes.
What controls the anomalous SST pattern formation remains an open question. For the ST forcing, the formation of strong meridional SST gradient (Fig. 13b) is straightforward given the prescribed forcing. The complex air-sea feedbacks, involving the interaction of atmospheric convection, circulation, cloud, and ocean dynamics, are potentially important in shaping the SST pattern (e.g., Xie et al. 2010, 2015). For example, more warming can also be found in the region with a large amount of mean low clouds (Fig. 5), reflecting the potential impact from the positive SST-stratocumulus feedback (e.g., Mechoso et al. 2016). We are also aware that changes in AET and OET may be partially responsible for the SST pattern formation. The detailed mechanisms leading to the SST pattern formation require further research. 

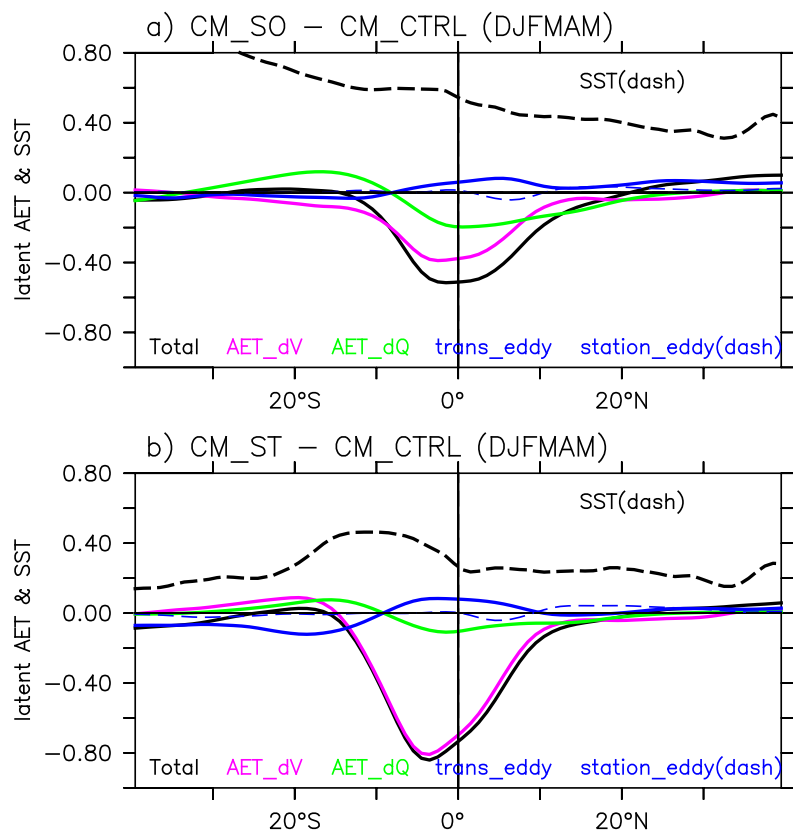

FIG. 13. (a) Changes in the total latent AET (black) with the SO forcing during December-May, and its individual components: the dynamic term (purple), thermodynamic term (from specific humidity and specific mass of ice; green), transient eddy term (blue), and stationary eddy term (dashed blue). The dashed black line shows the zonal mean SST change. (b) As in (a), but for the ST forcing case.

\section{f. Sensitivity of modeling results}

In this study, we force the ITCZ to shift southward by applying the TOA radiative heating in the Southern Hemisphere. However, the ITCZ shift is also sensitive to the sign of the radiative forcing. With the same magnitude of TOA radiative cooling forcing in the $\mathrm{SO}$ (CM_SO_COOL), we obtain a significantly weaker ITCZ shift (Fig. 15). In the equatorial region $\left(2^{\circ} \mathrm{S}-2^{\circ} \mathrm{N}\right)$, the ratio of the OET change to the AET change with the TOA cooling forcing is twice as strong as the TOA heating forcing (2.4 vs 1.2) (Fig. 15 vs Fig. 6a). Therefore, the partitioning of energy transport is also dependent on the sign of forcing.

The SO cooling forcing-induced PAI changes $(0.02 \pm$ 0.03 ) are insignificant and are only about $7 \%$ of the PAI changes from AM_Obs_SST to CM_CTRL (0.28) (Table 1). It is inferred that the radiation bias caused by the SO cloud bias is secondary in driving the formation of the DI problem, consistent with the other two model results (Kay et al. 2016; Hawcroft et al. 2016) but different from one model used in Mechoso et al. (2016). A diverse but coordinated model intercomparison is desired to understand such different sensitivity to the extratropical forcing from a process level.

By emphasizing the role of SST gradient in controlling the ITCZ position, it is natural to ask whether the results are dependent on the forcing profile particularly for the ST forcing case. The other sensitivity experiment is then conducted, with the same magnitude of TOA shortwave radiative forcing as CM_ST but using a step function of forcing in latitude in the ST. The resultant PAI changes are almost the same as that in CM_ST, although the maximum precipitation changes shift equatorward (not shown). Compared to the ST forcing case (Fig. 13b), a sharper meridional SST gradient is found but is confined to a smaller domain near the equator. It suggests that the ITCZ response is very likely independent of the forcing profile, and the results presented here are robust.

\section{Summary and discussion}

\section{a. Summary}

The spurious double ITCZ (DI) problem is a longstanding issue for current climate models, and broad discrepancies still persist in its origins. Motivated by several recent studies highlighting the potential role of radiation bias in driving the DI, this study examines the ITCZ shift resulting from the idealized radiative forcing over the Southern Ocean (SO) and the southern tropics (ST) using the one version of the GFDL model. Results demonstrate that the ITCZ position response to the ST forcing is twice as strong as the ST forcing. Numerical experiments demonstrate that the associated SST changes are crucial in driving the ITCZ shift. Compared to the SO forcing, the larger precipitation response to the ST radiative forcing is primarily controlled by the underlying SST pattern with a stronger meridional gradient.

One beauty of the energetic constraint framework in explaining the ITCZ shift is to avoid understanding the complex SST pattern. However, it has its caveat in explaining the ITCZ shift in these two perturbed experiments. The anomalous Hadley cell, showing a different vertical structure with the mean Hadley cell, almost does not contribute to transport the imposed energy from the Southern Hemisphere to the Northern Hemisphere. Different from the control simulation (CM_CTRL), changes in the cross-equatorial AET are dominated by the atmospheric transient eddy term when the ITCZ shift is most pronounced during DecemberMay. The strengthened atmospheric eddy activity is likely a consequence of the ITCZ shift through altering the meridional gradient of MSE. Whether atmospheric eddies are energetically constrained is also a question that is a fruitful direction for future research.

Results also show that the energy partitioning between the atmosphere and ocean is dependent on the 

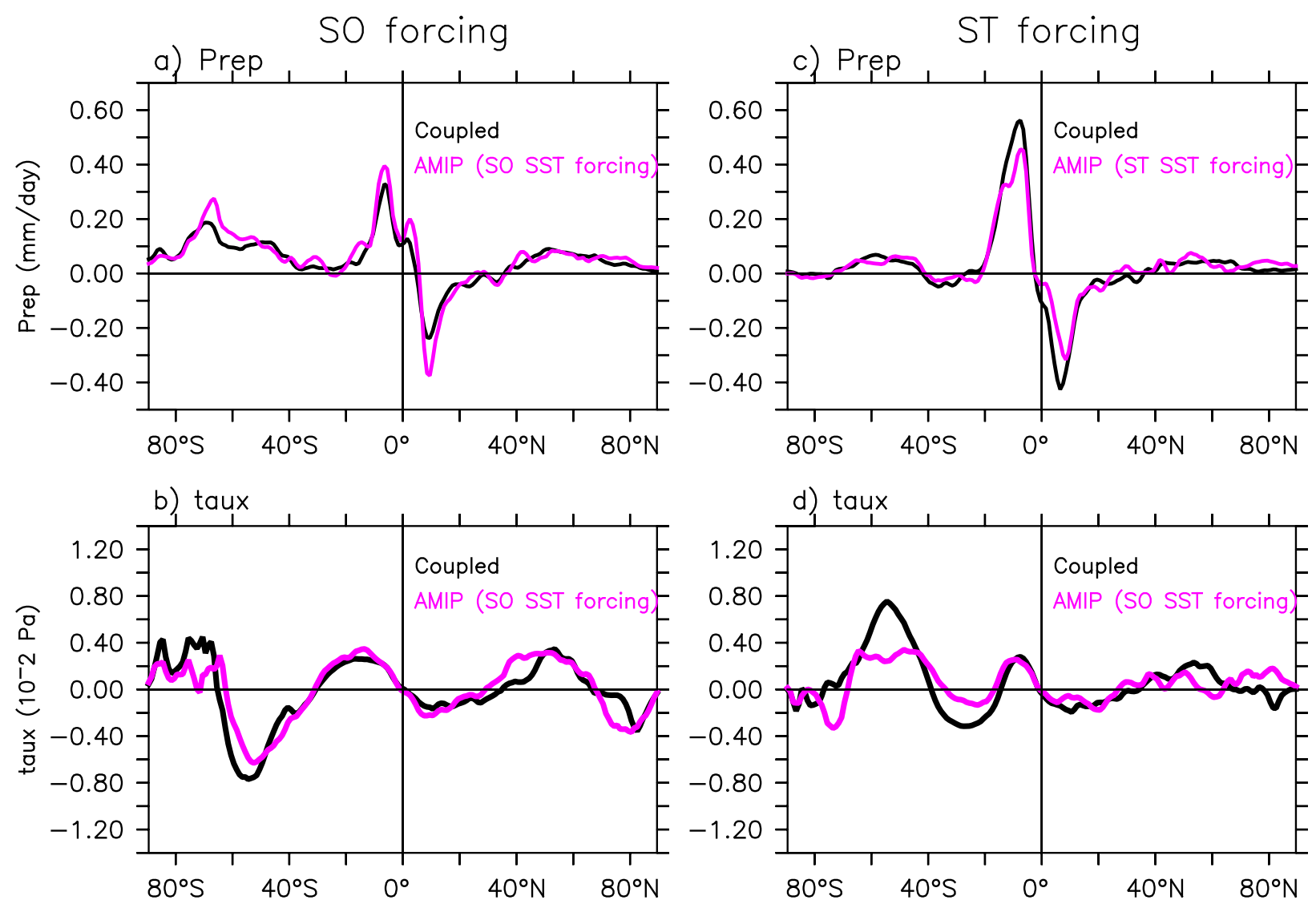

FIG. 14. Changes in annual and zonal mean (a) precipitation and (b) zonal wind stress with the SO radiative forcing. Black lines are from fully coupled experiments (CM_SO - CM_CTRL), and the purple lines show changes only resulting from the boundary layer SST changes but with normal insolation in AMIP-type simulations (AM_SO_SST - AM_CTRL). (c),(d) As in (a),(b), but for the ST forcing.

forcing latitude. Overall equivalent AET and OET responses are found for the extratropical SO forcing, while for the ST forcing, the imposed energy is nearly completely transported by the atmosphere. The contrasting partitioning of energy transport between the atmosphere and ocean originates from the different ocean heat uptake over the forcing domain, and also the different meridional scale of the anomalous ocean circulation. Over the equatorial region, the ocean circulation response is fairly similar to each other for these two cases, representing a tight coupling between the upperocean MOC and the changes in Hadley circulation through the trade winds (Green and Marshall 2017; Kang et al. 2018; Schneider 2017). Here we argue that the SST change pattern is an important medium in governing the partitioning of energy transport between the atmosphere and ocean, as it determines the changes in atmospheric temperature, convection, and surface wind stress. However, the SST itself should not be simply treated as a forcing in a coupled system. More effort is needed to investigate the formation of the anomalous SST pattern.

\section{b. Discussion}

Based on the control and perturbed experiments presented in this study, there are some implications:

(i) A two-level model may have its limitation in studying the Hadley circulation in a realistic configuration

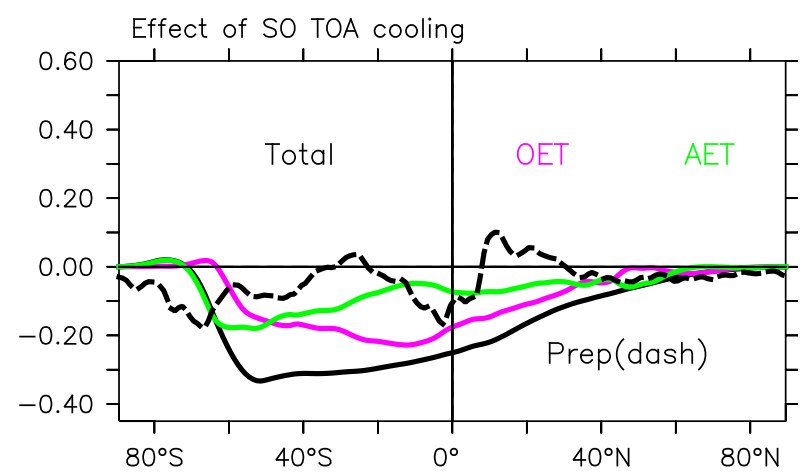

FIG. 15. As in Fig. 6a, but for the case with TOA cooling forcing in the SO. The magnitude of forcing is the same as that in the TOA heating experiment. 
considering the complex geographic distribution of deep and shallow convection and the associated different meridional circulations. A positive mean equatorial GMS in the control simulation does not necessitate altering the cross-equatorial AET associated with the anomalous Hadley circulation.

(ii) Both the atmospheric and oceanic eddies contribute substantially to the equatorial energy transport. Their effects were underappreciated to some extent in the past. It is of interest to note that the AET resulting from atmospheric eddies tends to be in the opposite direction to the OET resulting from oceanic eddies (Fig. 2). Meanwhile, atmospheric eddies have been shown to strongly affect the ITCZ width (Byrne and Schneider 2016).

(iii) Compared to the cross-equatorial AET, changes in the cross-equatorial OET show much stronger seasonality, characterized by strong northward energy transport during December-May but southward energy transport during the other seasons (Figs. 10c,f). This is indicative of anomalous heat storage in the southern tropics during JuneNovember. The total cross-equatorial OET is strongly coupled to the ITCZ migration, while such a relationship is not seen between the total cross-equatorial AET and ITCZ migration in the perturbed experiments (Figs. 10c,f).

(iv) The relationship between the annual mean ITCZ position and the annual mean cross-equatorial AET is potentially misleading in terms of causality if the seasonality of ITCZ position differs from that of cross-equatorial AET. For example, in this study, the dominant term for changes in crossequatorial AET is the GMS change term, while it is not directly linked to the ITCZ shift according to their distinctly different seasonality (Fig. 11).

(v) Whether the energetic constraint framework or the boundary layer SST gradient is more fundamental in driving tropical precipitation is still open to debate (e.g., Neelin and Held 1987; Kang and Held 2012; Lindzen and Nigam 1987; Back and Bretherton 2009). Many previous studies also demonstrated the effectiveness of the energetic constraint framework in relatively idealized configurations, such as the atmospheric model coupled to the slab-ocean model in an aquaplanet setting. The energetic constraint theory also works well in explaining the seasonality of ITCZ shift in the coupled control simulation (Fig. 3) but not in our perturbed experiments. It should be noted that these two theories are linked to some extent as the SST change is partially set by energy transport.
Here we applied the forcing at TOA to mimic the impacts of cloud biases. Whether the tropical precipitation response is model and forcing-type dependent is an open question. Interestingly, Haywood et al. (2016) found similar atmospheric responses and crossequatorial energy transport when forcing in clouds, with aerosols, or at the ocean surface using the HadGEM2-ES model. Furthermore, the energy transport and the ITCZ response to given perturbations are also sensitive to convection parameterization associated with the cloud-radiative feedback (Voigt et al. 2014; Frierson and Hwang 2012; Kang et al. 2009; Stevens and Bony 2013; Mechoso et al. 2016), convection-circulation feedback (Hess et al. 1993; Möbis and Stevens 2012), water vapor feedbacks (Clark et al. 2018), and ocean circulation (Fučkar et al. 2013). More research is required on this topic, but this is beyond the scope of this work.

Acknowledgments. The authors benefitted from the review comments from Isaac Held, Ángel AdamesCorraliza, and Stephen Griffies and from a discussion with Dargan Frierson. We thank David Paynter and Zhaoyi Shen for their technical help. The work is supported by NOAA's Climate Program Office, Climate Variability and Predictability Program (GC14252). S. M. Kang was supported by the Basic Science Research Program through the National Research Foundation of Korea (NRF) funded by the Ministry of Science, ICT, and Future Planning (2016R1A1A3A04005520). The authors acknowledge the World Climate Research Programme's (WCRP) Working Group on Coupled Modelling (WGCM), which is responsible for CMIP.

\section{REFERENCES}

Adler, R. F., and Coauthors, 2003: The Version-2 Global Precipitation Climatology Project (GPCP) monthly precipitation analysis (1979-present). J. Hydrometeor., 4, 1147-1167, https://doi.org/10.1175/1525-7541(2003)004<1147: TVGPCP $>2.0 . C O ; 2$.

Back, L. E., and C. S. Bretherton, 2009: On the relationship between SST gradients, boundary layer winds, and convergence over the tropical oceans. J. Climate, 22, 4182-4196, https:// doi.org/10.1175/2009JCLI2392.1.

Bacon, S., and N. Fofonoff, 1996: Oceanic heat flux calculation. J. Atmos. Oceanic Technol., 13, 1327-1329, https://doi.org/ 10.1175/1520-0426(1996)013<1327:OHFC>2.0.CO;2.

Bellucci, A., S. Gualdi, and A. Navarra, 2010: The double-ITCZ syndrome in coupled general circulation models: The role of large-scale vertical circulation regimes. J. Climate, 23, 11271145, https://doi.org/10.1175/2009JCLI3002.1.

Broccoli, A. J., K. A. Dahl, and R. J. Stouffer, 2006: Response of the ITCZ to Northern Hemisphere cooling. Geophys. Res. Lett., 33, L01702, https://doi.org/10.1029/2005GL024546. 
Byrne, M. P., and T. Schneider, 2016: Narrowing of the ITCZ in a warming climate: Physical mechanisms. Geophys. Res. Lett., 43, 11350-11 357, https://doi.org/10.1002/2016GL070396.

Chiang, J. C. H., and C. M. Bitz, 2005: Influence of high latitude ice cover on the marine intertropical convergence zone. Climate Dyn., 25, 477-496, https://doi.org/10.1007/s00382-005-0040-5.

Clark, S. K., Y. Ming, I. M. Held, and P. Phillipps, 2018: The role of the water vapor feedback in the ITCZ response to hemispherically asymmetric forcings. J. Climate, 31, 3659-3678, https://doi.org/10.1175/JCLI-D-17-0723.1.

Czaja, A., and J. Marshall, 2006: The partitioning of poleward heat transport between the atmosphere and ocean. J. Atmos. Sci., 63, 1498-1511, https://doi.org/10.1175/JAS3695.1.

Deser, C., R. A. Tomas, and L. Sun, 2015: The role of oceanatmosphere coupling in the zonal-mean atmospheric response to Arctic sea ice loss. J. Climate, 28, 2168-2186, https://doi.org/ 10.1175/JCLI-D-14-00325.1.

Donohoe, A., J. Marshall, D. Ferreira, and D. Mcgee, 2013: The relationship between ITCZ location and cross-equatorial atmospheric heat transport: From the seasonal cycle to the last glacial maximum. J. Climate, 26, 3597-3618, https://doi.org/ 10.1175/JCLI-D-12-00467.1.

Farneti, R., and G. K. Vallis, 2013: Meridional energy transport in the coupled atmosphere-ocean system: Compensation and partitioning. J. Climate, 26, 7151-7166, https://doi.org/10.1175/ JCLI-D-12-00133.1.

Frey, W. R., E. A. Maroon, A. G. Pendergrass, and J. E. Kay, 2017: Do Southern Ocean cloud feedbacks matter for 21st century warming? Geophys. Res. Lett., 44, 12 447-12 456, https:// doi.org/10.1002/2017GL076339.

Frierson, D. M. W., and Y.-T. Hwang, 2012: Extratropical influence on ITCZ shifts in slab ocean simulations of global warming. J. Climate, 25, 720-733, https://doi.org/10.1175/JCLI-D-1100116.1 .

Fučkar, N. S., S.-P. Xie, R. Farneti, E. A. Maroon, and D. M. W. Frierson, 2013: Influence of the extratropical ocean circulation on the intertropical convergence zone in an idealized coupled general circulation model. J. Climate, 26, 4612-4629, https:// doi.org/10.1175/JCLI-D-12-00294.1.

Green, B., and J. Marshall, 2017: Coupling of trade winds with ocean circulation damps ITCZ shifts. J. Climate, 30, 43954411, https://doi.org/10.1175/JCLI-D-16-0818.1.

Hawcroft, M., J. M. Haywood, M. Collins, A. Jones, A. C. Jones, and G. Stephens, 2016: Southern Ocean albedo, interhemispheric energy transports and the double ITCZ: Global impacts of biases in a coupled model. Climate Dyn., 48, 22792295, https://doi.org/10.1007/s00382-016-3205-5.

Haywood, J. M., and Coauthors, 2016: The impact of equilibrating hemispheric albedos on tropical performance in the HadGEM2-ES coupled climate model. Geophys. Res. Lett., 43, 395-403, https://doi.org/10.1002/2015GL066903.

Held, I. M., 2001: The partitioning of the poleward energy transport between the tropical ocean and atmosphere. J. Atmos. Sci., 58, 943-948, https://doi.org/10.1175/1520-0469(2001) 058<0943:TPOTPE > 2.0.CO;2.

Hess, P. G., D. S. Battisti, and P. J. Rasch, 1993: Maintenance of the intertropical convergence zone and the large-scale tropical circulation on a water-covered Earth. J. Atmos. Sci., 50, 691-713, https://doi.org/10.1175/1520-0469(1993)050<0691: MOTICZ $>2.0 . C O ; 2$.

Hill, S. A., Y. Ming, and I. M. Held, 2015: Mechanisms of forced tropical meridional energy flux change. J. Climate, 28, 17251742, https://doi.org/10.1175/JCLI-D-14-00165.1.
Hirota, N., Y. N. Takayabu, M. Watanabe, and M. Kimoto, 2011: Precipitation reproducibility over tropical oceans and its relationship to the double ITCZ problem in CMIP3 and MIROC5 climate models. J. Climate, 24, 4859-4873, https:// doi.org/10.1175/2011JCLI4156.1.

Hwang, Y.-T., and D. M. W. Frierson, 2013: Link between the double-intertropical convergence zone problem and cloud biases over the Southern Ocean. Proc. Natl. Acad. Sci. USA, 110, 4935-4940, https://doi.org/10.1073/pnas.1213302110.

Jayne, S. R., and J. Marotzke, 2002: The oceanic eddy heat transport. J. Phys. Oceanogr., 32, 3328-3345, https://doi.org/ 10.1175/1520-0485(2002)032<3328:TOEHT>2.0.CO;2.

Kang, S. M., and I. M. Held, 2012: Tropical precipitation, SSTs and the surface energy budget: A zonally symmetric perspective. Climate Dyn., 38, 1917-1924, https://doi.org/10.1007/s00382-011-1048-7.

- , and S.-P. Xie, 2014: Dependence of climate response on meridional structure of external thermal forcing. J. Climate, 27, 5593-5600, https://doi.org/10.1175/JCLI-D-13-00622.1.

- I. M. Held, D. M. W. Frierson, and M. Zhao, 2008: The response of the ITCZ to extratropical thermal forcing: Idealized slab-ocean experiments with a GCM. J. Climate, 21, 35213532, https://doi.org/10.1175/2007JCLI2146.1.

, D. M. W. Frierson, and I. M. Held, 2009: The tropical response to extratropical thermal forcing in an idealized GCM: The importance of radiative feedbacks and convective parameterization. J. Atmos. Sci., 66, 2812-2827, https://doi.org/ 10.1175/2009JAS2924.1.

, Y. Shin, and S.-P. Xie, 2018: Extratropical forcing and tropical rainfall distribution: Energetics framework and ocean Ekman advection. npj Climate Atmos. Sci., 1, 2, https://doi.org/ 10.1038/s41612-017-0004-6.

Kay, J. E., C. Wall, V. Yettella, B. Medeiros, C. Hannay, P. Caldwell, and C. Bitz, 2016: Global climate impacts of fixing the Southern Ocean shortwave radiation bias in the Community Earth System Model (CESM). J. Climate, 29, 4617-4636, https://doi.org/10.1175/JCLI-D-15-0358.1.

Lin, J.-L., 2007: The double-ITCZ problem in IPCC AR4 coupled GCMs: Ocean-atmosphere feedback analysis. J. Climate, 20, 4497-4525, https://doi.org/10.1175/JCLI4272.1.

Lindzen, R. S., and S. Nigam, 1987: On the role of sea surface temperature gradients in forcing low-level winds and convergence in the tropics. J. Atmos. Sci., 44, 2418-2436, https:// doi.org/10.1175/1520-0469(1987)044<2418:OTROSS >2.0.CO;2.

Magnusdottir, G., and R. Saravannan, 1999: The response of atmospheric heat transport to zonally averaged SST trends. Tellus, 51A, 815-832, https://doi.org/10.3402/tellusa.v51i5.14495.

McGee, D., A. Donohoe, J. Marshall, and D. Ferreira, 2014: Changes in ITCZ location and cross-equatorial heat transport at the last glacial maximum, Heinrich Stadial 1, and the midHolocene. Earth Planet. Sci. Lett., 390, 69-79, https://doi.org/ 10.1016/j.epsl.2013.12.043.

Mechoso, C. R., and Coauthors, 1995: The seasonal cycle over the tropical Pacific in coupled ocean-atmosphere general circulation models. Mon. Wea. Rev., 123, 2825-2838, https://doi.org/ 10.1175/1520-0493(1995)123<2825:TSCOTT > 2.0.CO;2.

— - and Coauthors, 2016: Can reducing the incoming energy flux over the Southern Ocean in a CGCM improve its simulation of tropical climate? Geophys. Res. Lett., 43, 11057-11063, https://doi.org/10.1002/2016GL071150.

Merlis, T. M., T. Schneider, S. Bordoni, and I. Eisenman, 2013: Hadley circulation response to orbital precession. Part I: Aquaplanets. J. Climate, 26, 740-753, https://doi.org/10.1175/ JCLI-D-11-00716.1. 
Möbis, B., and B. Stevens, 2012: Factors controlling the position of the intertropical convergence zone on an aquaplanet. $J . A d v$. Model. Earth Syst., 4, M00A04, https://doi.org/10.1029/ 2012MS000199.

Myhre, G., and Coauthors, 2013: Anthropogenic and natural radiative forcing. Climate Change 2013: The Physical Science Basis, T. F. Stocker et al., Eds., Cambridge University Press, 659-740, https://doi.org/10.1017/CBO9781107415324.018.

Neelin, J. D., and I. M. Held, 1987: Modeling tropical convergence based on the moist static energy budget. Mon. Wea. Rev., 115, 3-12, https://doi.org/10.1175/1520-0493(1987)115<0003: MTCBOT>2.0.CO;2.

Oort, A. H., 1971: The observed annual cycle in the meridional transport of atmospheric energy. J. Atmos. Sci., 28, 325339, https://doi.org/10.1175/1520-0469(1971)028<0325: TOACIT $>2.0 . \mathrm{CO} ; 2$.

Peters, M. E., Z. Kuang, and C. C. Walker, 2008: Analysis of atmospheric energy transport in ERA-40 and implications for simple models of the mean tropical circulation. J. Climate, 21, 5229-5241, https://doi.org/10.1175/2008JCLI2073.1.

Rayner, N. A., D. E. Parker, E. B. Horton, C. K. Folland, L. V. Alexander, D. P. Rowell, E. C. Kent, and A. Kaplan, 2003: Global analyses of sea surface temperature, sea ice, and night marine air temperature since the late nineteenth century. J. Geophys. Res., 108, 4407, https://doi.org/10.1029/ 2002JD002670.

Richter, I., 2015: Climate model biases in the eastern tropical oceans: Causes, impacts and ways forward. Wiley Interdiscip. Rev.: Climate Change, 6, 345-358, https://doi.org/10.1002/ wcc. 338 .

Rose, B. E. J., K. C. Armour, D. S. Battisti, N. Feldl, and D. D. B. Koll, 2014: The dependence of transient climate sensitivity and radiative feedbacks on the spatial pattern of ocean heat uptake. Geophys. Res. Lett., 41, 1071-1078, https://doi.org/ 10.1002/2013GL058955.

Schneider, T., 2017: Feedback of atmosphere-ocean coupling on shifts of the intertropical convergence zone. Geophys. Res. Lett., 44, 11 644-11 653, https://doi.org/10.1002/2017GL075817.

— T. Tischoff, and G. H. Haug, 2014: Migrations and dynamics of the intertropical convergence zone. Nature, 513, 45-53, https://doi.org/10.1038/nature13636.

Seo, J., S. M. Kang, and D. M. W. Frierson, 2014: Sensitivity of intertropical convergence zone movement to the latitudinal position of thermal forcing. J. Climate, 27, 3035-3042, https:// doi.org/10.1175/JCLI-D-13-00691.1.

- _ — , and T. Merlis, 2017: A model intercomparison of the tropical precipitation response to $\mathrm{a}_{2}$ doubling in aquaplanet simulations. Geophys. Res. Lett., 44, 993-1000, https:// doi.org/10.1002/2016GL072347.

Song, F., and G. J. Zhang, 2017: Impact of tropical SSTs in the North Atlantic and southeastern Pacific on the eastern Pacific
ITCZ. J. Climate, 30, 1291-1305, https://doi.org/10.1175/JCLID-16-0310.1.

Stevens, B., and S. Bony, 2013: What are climate models missing? Science, 340, 1053-1054, https://doi.org/10.1126/science.1237554.

Taylor, K. E., R. J. Stouffer, and G. A. Meehl, 2012: An overview of CMIP5 and the experiment design. Bull. Amer. Meteor. Soc., 93, 485-498, https://doi.org/10.1175/BAMS-D-11-00094.1.

Tomas, R. A., C. Deser, and L. Sun, 2016: The role of ocean heat transport in the global climate response to projected Arctic sea ice loss. J. Climate, 29, 6841-6859, https://doi.org/10.1175/ JCLI-D-15-0651.1.

Trenberth, K. E., and J. T. Fasullo, 2010: Simulation of present-day and twenty-first-century energy budgets of the Southern Oceans. J. Climate, 23, 440-454, https://doi.org/10.1175/2009JCLI3152.1.

Vecchi, G. A., and Coauthors, 2014: On the seasonal forecasting of regional tropical cyclone activity. J. Climate, 27, 7994-8016, https://doi.org/10.1175/JCLI-D-14-00158.1.

Voigt, A., B. Stevens, J. Bader, and T. Mauritsen, 2014: Compensation of hemispheric albedo asymmetries by shifts of the ITCZ and tropical clouds. J. Climate, 27, 1029-1045, https:// doi.org/10.1175/JCLI-D-13-00205.1.

Wielicki, B. A., B. R. Barkstrom, E. F. Harrison, R. B. Lee III, G. Louis Smith, and J. E. Cooper, 1996: Clouds and the Earth's Radiant Energy System (CERES): An Earth observing system experiment. Bull. Amer. Meteor. Soc., 77, 853-868, https://doi.org/ 10.1175/1520-0477(1996)077<0853:CATERE >2.0.CO;2.

Xiang, B., W. Yu, T. Li, and B. Wang, 2011: The critical role of the boreal summer mean state in the development of the IOD. Geophys. Res. Lett., 38, L02710, https://doi.org/10.1029/ 2010GL045851.

_ B. Bang, W. Yu, and S. Xu, 2013: How can anomalous western North Pacific subtropical high intensify in late summer? Geophys. Res. Lett., 40, 2349-2354, https://doi.org/10.1002/grl.50431.

_ , M. Zhao, I. M. Held, and J.-C. Golaz, 2017: Predicting the severity of spurious "double ITCZ" problem in CMIP5 coupled models from AMIP simulations. Geophys. Res. Lett., 44, 1520-1527, https://doi.org/10.1002/2016GL071992.

Xie, S.-P., C. Deser, G. A. Vecchi, J. Ma, H. Teng, and A. T. Wittenberg, 2010: Global warming pattern formation: Sea surface temperature and rainfall. J. Climate, 23, 966-986, https://doi.org/10.1175/2009JCLI3329.1.

— , and Coauthors, 2015: Towards predictive understanding of regional climate change. Nat. Climate Change, 5, 921-930, https://doi.org/10.1038/nclimate2689.

Zhang, G. J., and H. Wang, 2006: Toward mitigating the double ITCZ problem in NCAR CCSM3. Geophys. Res. Lett., 33, L06709, https://doi.org/10.1029/2005GL025229.

Zhao, M., and Coauthors, 2018: The GFDL global atmosphere and land model AM4.0/LM4.0: 1. Simulation characteristic with prescribed SSTs. J. Adv. Model. Earth Syst., 10, 691-734, https://doi.org/10.1002/2017MS001208. 